\title{
Release of insulin from PLGA-alginate dressing stimulates regenerative healing of burn wounds in rats
}

\begin{abstract}
Sandeep Dhall ${ }^{1}$, João P. Silva ${ }^{1,2}$, Yan Liu ${ }^{1,4}$, Michael Hrynyk ${ }^{5}$, Monika Garcia ${ }^{1}$, Alex Chan ${ }^{1}$, Julia Lyubovitsky ${ }^{3}$, Ronald J. Neufeld ${ }^{5}$, Manuela Martins-Green ${ }^{1, \#}$

${ }^{1}$ Department of Cell Biology and Neuroscience, ${ }^{2}$ Centre for Biological Engineering, University of Minho, Campus Gualtar, Braga, 4710-057, Portugal, ${ }^{3}$ Department of Bioengineering, University of California at Riverside, Riverside, California 92521, ${ }^{4}$ Department of Burn and Plastic Surgery, Rujin Hospital, Shanghai 200025, China, ${ }^{5}$ Department of Chemical Engineering, Queen's University, Kingston, K7L 3N6, Canada
\end{abstract}

\# Corresponding author: Manuela Martins-Green

Department of Cell Biology and Neuroscience,

University of California Riverside

900 University Avenue, BSB room 2217,

Riverside, CA 92521, USA

Tel: $1-951-827-2585$

Fax: 1-951-827-3087

Email:manuela.martins@ucr.edu

Conflicts of Interest: None of the authors has conflicts of interest related to this work.

Short running title: Insulin improves burn wound healing

Keywords: Oxidative stress, Macrophage, Neutrophils, Angiogenesis, Collagen 


\begin{abstract}
Burn wound healing involves a complex set of overlapping processes in an environment conducive to ischemia, inflammation, and infection costing $\$ 7.5$ billion/year in the US alone, in addition to the morbidity and mortality that occur when the burns are extensive. We previously showed that insulin, when topically applied to skin excision wounds, accelerates reepithelialization, and stimulates angiogenesis. More recently, we developed an alginate sponge dressing (ASD) containing insulin encapsulated in PLGA microparticles that provides a sustained release of bioactive insulin for $>20$ days in a moist and protective environment. We hypothesized that insulin-containing ASD accelerates burn healing and stimulates a more regenerative, less scarring, healing. Using a heat-induced burn injury in rats, we show that burns treated with dressings containing $0.04 \mathrm{mg}$ insulin $/ \mathrm{cm}^{2}$, every three days for 9 days, have faster closure, faster rate of disintegration of dead tissue, and decreased oxidative stress. In addition, in insulin-treated wounds the pattern of neutrophil inflammatory response suggests faster clearing of the burn dead tissue. We also observe faster resolution of the pro-inflammatory macrophages. We also found that insulin stimulates collagen deposition and maturation with the fibers organized more like a basket weave (normal skin) than aligned and crosslinked (scar tissue). In summary, application of ASD-containing insulin-loaded PLGA particles on burns every three days stimulates faster and more regenerative healing. These results suggest insulin as a potential therapeutic agent in burn healing and, because of its long history of safe use in humans, insulin could become one of the treatments of choice when repair and regeneration are critical for proper tissue function.
\end{abstract}




\section{INTRODUCTION}

The American Burn Association has reported that about 486,000 people/year received medical treatment for burn injuries over the past ten years [1]. Moreover, inadequate wound treatment leads to increased morbidity and impaired quality of life while consuming substantial health resources in developed countries [2]. Burns are one of the most devastating forms of soft tissue injury and are most commonly caused by exposure to heat, electricity, radiation, chemicals and/or friction [3]. The damage may only affect the epidermal layer of the skin (superficial burns), penetrate a part of the dermis (deep-partial thickness burns) or completely extend through both epidermal and dermal layers (full-thickness burns) [4].

During the first $48 \mathrm{~h}$ post-injury, cardiac output, oxygen consumption, decrease in metabolic rate and hyperglycemia associated with impaired glucose tolerance, occur [5, 6-8]. These parameters then gradually rise, developing a hyper-metabolic response, until a plateau is reached at five days after the burn. This response is most likely initiated by the secretion of several regulatory proteins including but not limited to hormones such as catecholamine, glucagon and dopamine, cytokines such as IL-1, IL-6 and TNF- $\alpha$, formation of neutrophil adherence complexes and reactive oxygen species, ultimately leading to protein and lipid catabolism [8,9]. The rise in oxygen consumption results from the increased energy requirements by major organs and tissues, such as liver and muscle [9]. During this early period, increases in inflammation, accompanied by endothelial cell dysfunction and microvascular permeability, result in edema [10]. Furthermore, intense metabolic changes associated with hyperglycemia and insulin resistance occur, which are common complications of severe burn [11].

The successful use of insulin on problematic wounds began in the 1930's with improvement in the healing of non-diabetic bed sores upon injections of insulin [12]. The topical use of insulin was later proven to effectively heal small, uncomplicated decubitus ulcers [13]. Insulin was then subcutaneously injected on scalded rats, and shown to promote faster healing, with better and thicker epidermal layer, abundant retia and higher number of cells in S-phase [14]. Moreover, local injection of long-acting insulin zinc suspension accelerated skin wound healing without major side effects [15]. Insulin administration to hospitalized burn patients also has been shown to enhance protein synthesis in the muscle and accelerate the healing process [16]. Although a variety of therapeutic agents, including growth factors such as epidermal growth factor (EGF) [17] or transforming growth factor beta (TGF- $\beta$ ) [18], hormones [19], simvastatin [20] and propranolol [21] have been successfully used in treating patients with burn wounds, the elevated costs associated with the production of these molecules discourages their application [22].

Tissue-engineered wound dressings have gained increasing interest as an approach towards more rapid wound healing, while reducing pain and discomfort to the patient. This results in faster rehabilitation with less extended hospital stays. Wound dressings should prevent bacterial infection and be non-toxic, biodegradable, capable of removing wound exudates and painless on both application and removal, while providing a moist environment to the wound area [23, 24]. Among the different types of wound dressings, alginates have been used because of their hemostatic properties during burn healing $[25,26]$. Alginate is a low-cost, linear, unbranched polysaccharide, obtained from brown seaweed, comprising different amounts of $(1 \rightarrow 4) \beta$-Dmannuronic and $\alpha$-L-guluronic acid units. It is biocompatible, non-toxic, non-immunogenic, biodegradable and can undergo gelation upon addition of divalent ions, such as calcium [24, 26$]$. 
We have recently published a procedure describing encapsulation of human recombinant insulin in poly(D, L-lactic-co-glycolic acid) (PLGA) microspheres [27]. Using this system we obtained sustained release of insulin in aqueous solution for up to 25 days. In order to achieve an effective insulin stabilization and release in the wound tissue, insulin-loaded PLGA microspheres were further incorporated into alginate sponge dressings [22]. This resulted in the sustained release of insulin, while providing a moist environment and protection to the wounds. Here we show that slow release of insulin from PLGA particles in alginate dressings stimulates healing of burn wounds and that the healing occurs with less scarring.

\section{MATERIALS AND METHODS}

Reagents: Human recombinant crystalline insulin (hRcI), poly-(ethylene glycol) (PEG) (avg MW $1450 \mathrm{Da}$ and $10 \mathrm{kDa}$ ), poly(vinyl alcohol) (PVA) (avg MW 13-23 kDa), CaCl2, $\mathrm{NaCl}, \mathrm{NaOH}$, and sodium dodecyl sulfate (SDS) were supplied by Sigma Aldrich (Oakville, Canada). PLGA (D,L; 50:50, avg $17 \mathrm{kDa}$ ) was obtained from Purac Biomaterials (Lincolnshire, U.S.A.). Dichloromethane (DCM) was supplied by Caledon Laboratories (Georgetown, Canada). Protanal LF10/60 LS (35-45\% guluronic/55-65\% mannuronic) was obtained from FMC Biopolymer (Philadelphia, U.S.A.). A Micro BCA protein assay kit was obtained through ThermoFisher (Ottawa, Canada). Other materials were obtained as follows: Vectashield from Vector Laboratories (Burlingame, CA); trichrome stain kit from ScyTek Laboratories (Logan, UT); ketamine, xylazine, buprenorphine, from Henry Schein (Melville, NY).

Microparticle and Alginate Sponge Dressing Preparation: A solid-in-oil-in-water (S/O/W) method was used to encapsulate crystalline insulin in PLGA microparticles, then embedded in an alginate sponge dressing as previously described [22, 27]. Circular alginate sponge dressings (ASD) were stored at $-20^{\circ} \mathrm{C}$ until use. Before application, ASDs were sterilized under UV light for 20 min each side.

Burn wound model: Animal studies were approved by the Institutional Animal Care and Use Committee (IACUC) of the University of California, Riverside. Female adult Sprague-Dawley rats weighing 200-240 g were obtained from the University of California Riverside vivarium and housed under a $12 \mathrm{~h}$ dark/light cycle in a room with controlled temperature and humidity. Animals were supplied with standard rat chow and water ad libitum. Prior to burning, the rats were anesthetized with an intraperitoneal dose of $80 \mathrm{mg} / \mathrm{kg}$ ketamine and $16 \mathrm{mg} / \mathrm{kg}$ xylazine. The analgesic buprenorphine $(0.05-0.1 \mathrm{mg} / \mathrm{kg})$ was administered right after the burn to prevent postburn pain. Photographs of the wounds were taken using a digital camera at a distance of $4 \mathrm{~cm}$ and wound size was then determined using ImageJ software (NIH, Bethesda, MD) overtime during healing until re-epithelialization was achieved. Wound tissues were collected $1 \mathrm{~h}$ after the burn was made and at different time points postburn for tissue analysis. Normal skin was also collected from an area distant from the burn. Over the period of the experiment, levels of blood glucose were monitored with an electronic glucose meter (Bayer; Tarrytown, USA) and animal weight determined using a digital electronic scale (Mettler Toledo; Columbus, USA). Insulin levels in the tissues were measured using a commercially available kit (Abcam, Cambridge, MA). Insulin in the tissue samples was bound to an immobilized antibody and then conjugated with biotinylated insulin antibody that was further bound to HRP-conjugated Streptavidin. A chromogenic substrate solution was then added to develop color that was read at $450 \mathrm{~nm}$ and expressed as $\mu \mathrm{LU} / \mathrm{mL}$. 
Histological procedures: At different time points, tissue was collected for histology by excising the wound tissues, including an area of $5 \mathrm{~mm}$ around the wound edge. Tissues were fixed in $4 \%$ paraformaldehyde for $2 \mathrm{~h}$, followed by $1 \mathrm{~h}$ incubation with $0.1 \mathrm{M}$ glycine/PBS and two incubations with $15 \%$ and $30 \%$ sucrose, for $\sim 6 \mathrm{~h}$ and overnight, respectively. Tissues were then embedded in OCT (Tissue-Tek; Torrance, USA), frozen in a mixture of ethanol/dry ice slush and stored at $80^{\circ} \mathrm{C}$. Sections were stained with Hematoxylin and Eosin and with a modified Masson's Trichrome stain, as previously described [28]. Sections were visualized using a Nikon Microphot-FXA microscope with a Nikon DS-Fil digital camera. Collagen stained blue, while keratin showed a red color, cytoplasm stained pink and cell nuclei were black.

Second Harmonic Generation (SHG) imaging: Collagen's intrinsic second harmonic generation signal were detected by using an inverted Zeiss LSM 510 NLOMETA laser scanning microscope (Carl Zeiss Microscopy, LLC, Thornwood, NY) based on the Axiovert 200M inverted microscope equipped with standard illumination systems for transmitted light and epifluorescence detection. This microscope was also equipped with an NLO interface for a femtosecond Titanium-Sapphire laser excitation source (Chameleon-Ultra, Coherent, Inc., Santa Clara, CA) for multiphoton excitation. The Chameleon laser provided femtosecond pulses at a repetition rate of about $80 \mathrm{MHz}$, with the center frequency tunable from 690 to $1040 \mathrm{~nm}$. Images were acquired with a long working distance objective (Zeiss, 40X water, N.A. 0.8). The two-photon signals from the sample were epicollected and discriminated by the short pass $650 \mathrm{~nm}$ dichroic beam splitter. The SHG images were collected using a META detection module with signals sampled in a 394-405 nm detection range $\left(\lambda_{\text {exc }}=800 \mathrm{~nm}\right)$. Each image presented in this work is 12 bit, $512 \times 512$ pixels representing $225 \mu \mathrm{m} \times 225 \mu \mathrm{m}$ field of view.

Immunolabeling procedure: Frozen sections were fixed in 4\% paraformaldehyde for $20 \mathrm{~min}$, rinsed with PBS, incubated in a solution of $0.1 \mathrm{M}$ glycine in PBS for $20 \mathrm{~min}$ and blocked in $10 \%$ non-immune serum of the secondary antibody species in PBS containing $0.1 \%$ Triton X-100 for $30 \mathrm{~min}$. Slides were then incubated for $2 \mathrm{~h}$ at room temperature with the primary antibodies in $1 \%$ BSA/PBS. The primary antibodies used, and respective dilutions, were the following: 1:200 FITClabeled mouse anti-rat $\alpha$-smooth muscle actin ( $\alpha$-SMA, Sigma-Aldrich, St Louis, MO) and 1:100 rabbit anti-rat myeloperoxidase (MPO, eBioscience, San Diego, CA). Sections were then washed three times with $0.1 \%$ BSA in PBS and incubated with 1:25 goat anti-rabbit or 1:100 goat antimouse dilutions of FITC-labeled, or 1:100 goat anti-rabbit Alexa Fluor 594-labeled secondary antibodies (Life Technologies, Grand Island, NY), for $1 \mathrm{~h}$ at room temperature. After washing, sections were mounted in Vectashield containing DAPI (Vector Laboratories, Inc. Berlingame, CA). Immunofluorescence was visualized and imaged using a Nikon Microphot-FXA fluorescence microscope with a Nikon DS-Fil digital camera and Nikon NIS-Elements software (Nikon Instruments Inc., Melville, NY).

Flow cytometry assay: Tissues disaggregation and digestion were performed in 4ml of RPMI in presence of collagenase Type 1 (Worthington Biochemical Corp., Lakewood,NJ) at $37^{0} \mathrm{C}$ for 45 min. Dissociated tissues were passed through 2-3 times through an 18 gauge needle and then a 20 gauge needle. Harvested cells were washed with RPMI. Single cell suspension was obtained by straining the homogenate via cell strainers. Single cells were then washed with RPMI and stained with CD80, CD 86 (eBioscience, San Diego, CA) and CD 163 (AbD Serotec, Raleigh, NC) for 30 
min. Cells for isotype controls were obtained from the single cell populations and stained with Isotype Control APC, Isotype Control FITC and Isotype Control PE (eBioscience, San Diego, CA). Stained cells were washed with RPMI, suspended in FACS buffer and read using FACSAria Cell Sorting System (BD Biosciences, San Jose, CA). Analysis of data was performed using FLOWJO software (FLOWJO, LLC, Ashland,OR)

Cytokines expression: Burn wound tissues were homogenized as described above. ProcartaPlex ${ }^{\mathrm{TM}}$ cytokine immunoassay was performed according to the manufacturers' protocol (eBioscience, Carlsbad, CA) using equilibrated protein tissue homogenate. Level of interleukin-10 (IL-10) was quantified using a Luminex ${ }^{\mathrm{TM}} 200$ instrument (Millipore, Billerica, MA) by monitoring the fluorescence associated with the bead set.

In vivo angiogenesis assay: The hair on the backs of C57BL/6 mice was removed using Nair (Madera, CA). The next day, they were injected subcutaneously with either insulin (Humulin, Indianapolis,IN) $(1 \mu \mathrm{g} / 15 \mu \mathrm{l}$ saline) or $15 \mu \mathrm{l}$ saline using an insulin syringe. Both insulin and PBS were injected in different sites of the back of each mouse every 24 hrs for 4 days. The areas surrounding the injection sites were labeled using a permanent marker to ensure that the injections were always done at the same site. A possible position-dependent effect was discarded by changing the site of insulin and PBS administration from mouse to mouse. Skin samples from the injected areas were collected and observed at day 5 . Blood vessels were highlighted using ImageJ software (NIH, Bethesda, MD). Briefly, the scale for all the images was set using a ruler with known distance and ImageJ function Analyze-->Scale. The free hand selection tool was used to trace and highlight the blood vessels and the image was saved. The total vessel length was then evaluated using the analyze function in ImageJ.

VE-cadherin expression was quantified by Western-blot. Burn wound tissues were homogenized in RIPA buffer as previously described and protein quantified using the DC protein assay kit (BioRad, Hercules, CA). Equal amounts of protein for each sample were mixed with sample buffer, boiled for $5 \mathrm{~min}$, and analyzed using a 10\% SDS-PAGE. Following one hour blocking in 5\% bovine serum albumin (BSA), the immunoblotting was performed by incubating the membrane with 1:1000 rabbit anti-mouse VE-cadherin (phosphor Y731) primary antibody (Abcam, Cambridge, MA) overnight at $4^{\circ} \mathrm{C}$. Blots were then washed and incubated with the appropriate horseradish peroxidase (HRP)-conjugated goat anti-rabbit secondary antibody, followed by a $5 \mathrm{~min}$ incubation with West Dura extended duration substrate (Pierce Biotechnology, Thermo Fisher Scientific Inc., Rockford, IL). Blots were also probed for GAPDH (1:1000, Cell Signaling, Boston, MA), a housekeeping protein to evaluate equal loading. Band intensities were quantified with Image Lab 5.0 (Bio-Rad, Berkeley, CA) and normalized against the GAPDH control. Results were then expressed as fold change relatively to the control.

Determination of the antioxidant status in wounded tissues: Antioxidant enzymes activity was detected in the tissue extracts as previously described [29]. Briefly, tissues (40-50 mg) were homogenized in a bullet blender for $5 \mathrm{~min}$ at $4^{\circ} \mathrm{C}$ using zirconium oxide beads and $10 \mu \mathrm{R}$ RIPA buffer ( $1 \%$ NP-40, $0.1 \%$ SDS, $50 \mathrm{mM}$ Tris-HCl pH 7.4, $150 \mathrm{mM} \mathrm{NaCl,} 0.5 \%$ sodium deoxycholate, $1 \mathrm{mM}$ EDTA) per $\mathrm{mg}$ of tissue. The extracts were then centrifuged at 12,000 rpm for $15 \mathrm{~min}$, at $4^{\circ} \mathrm{C}$. The supernatants were either immediately used or aliquoted and stored at $-80^{\circ} \mathrm{C}$ for later use.

Superoxide dismutase (SOD) activity in the tissues was determined using a commercially 
available kit (Cayman Chemical, Ann Arbor, USA), according to the manufacturer's protocol. Results were expressed as U/ml of tissue extract, one unit of SOD being defined as the amount of enzyme needed to achieve $50 \%$ dismutation of the superoxide radical.

Hydrogen peroxide $\left(\mathrm{H}_{2} \mathrm{O}_{2}\right)$ levels in the tissues were measured using a commercially available kit (Cell Technology Inc., Mountain View, USA). The assay is based on the peroxidasecatalyzed oxidation by $\mathrm{H}_{2} \mathrm{O}_{2}$ of the non-fluorescent substrate 10-acetyl-3,7-dihydroxyphenoxazine to a fluorescent resorufin read fluorometrically at $530 \mathrm{~nm}$ (excitation)/590 nm (emission) using a Victor 2 microplate reader. The amount of $\mathrm{H}_{2} \mathrm{O}_{2}$ in the supernatants was calculated from a standard curve generated with known concentrations of $\mathrm{H}_{2} \mathrm{O}_{2}$.

Catalase activity in the tissues was measured using a commercial kit (Cayman Chemical, Ann Arbor, USA), according to the manufacturer's procedure. This assay is based on the peroxidase ability of catalase together with methanol to produce formaldehyde in the presence of an optimal concentration of $\mathrm{H}_{2} \mathrm{O}_{2}$. This formaldehyde was then quantified spectrophotometrically at $540 \mathrm{~nm}$ using 4-amino-3-hydrazino-5-mercapto-1,2,4-triazole (purpald) as the chromogen. Catalase activity was expressed as $\mathrm{nmol} / \mathrm{min} / \mathrm{ml}$.

Glutathione peroxidase (GPx) activity was measured indirectly by a coupled reaction with glutathione reductase (GR), using a commercially available kit (Cayman Chemical, Ann Arbor, USA). GPx reduces $\mathrm{H}_{2} \mathrm{O}_{2}$ to $\mathrm{H}_{2} \mathrm{O}$, while producing oxidized glutathione (GSSG) in the process, which is then recycled to its reduced state by GR and NADPH. Oxidation of NADPH to NADP ${ }^{+}$ is accompanied by a decrease in absorbance at $340 \mathrm{~nm}$. Under rate-limiting conditions of GPx activity, the rate of decrease in the absorbance measured at $340 \mathrm{~nm}$, read at 1-min interval during a total of $5 \mathrm{~min}$ in a Victor 2 microplate reader, will be directly proportional to the GPx activity of the sample. GPx activity was expressed as $\mathrm{nmol} / \mathrm{min} / \mathrm{ml}$ of tissue extract.

DNA damage assay: 5-6 mg of wound tissue were collected and homogenized in RIPA buffer, as described above. DNA was then extracted using the DNeasy Blood and Tissue kit (Qiagen, Chatsworth, CA) according to the manufacturer's protocol. DNA concentration was measured and purity confirmed by determining the $\mathrm{OD}_{260} / \mathrm{OD}_{280}$ absorption ratio. The levels of 8-hydroxy-2'deoxyguanosine $(8-\mathrm{OH}-\mathrm{dG})$, which correlate with the amount of oxidative DNA damage, were measured spectrophotometrically at $405 \mathrm{~nm}$ using a DNA/RNA Oxidative Damage EIA kit (Cayman Chemical, Ann Arbor, USA) per the manufacturer's instructions.

Lipid peroxidation assay: Thiobarbituric acid reactive substances (TBARS), an indicator of lipid peroxidation in the tissues, were measured by using a commercially available kit (Cell Biolabs Inc., San Diego, USA). Byproducts of lipid peroxidation, like malondialdehyde (MDA) and 4hydroxynonenal (4-HNE), form adducts with TBARS that can be detected fluorometrically at 540 $\mathrm{nm} / 590 \mathrm{~nm}$ excitation/emission. TBARS levels were then calculated from a predetermined MDA standard curve.

Protein nitration assay: Nitrotyrosine levels in the tissue were measured by an enzyme immunoassay, using a commercially available kit (Cell Biolabs Inc., San Diego, USA). Briefly, tissue samples were incubated with an anti-nitrotyrosine primary antibody, followed by a horseradish peroxidase (HRP)-conjugated secondary antibody and enzyme substrate, in an ELISA plate. Nitrotyrosine content was then measured spectrophotometrically at $412 \mathrm{~nm}$ against a standard curve prepared from predetermined nitrated BSA standards.

Statistical Analysis: Statistical analysis was performed using GraphPad Prism 5 (GraphPad Software, La Jolla, CA). A one-way ANOVA, followed by a pairwise comparison post-test, was conducted wherever appropriate. A 95\% confidence interval was considered as statistical 
significant.

\section{RESULTS}

Partial thickness burn wounds were made on the dorsum of anesthetized rats with a $1.5 \mathrm{~cm}$ diameter brass cylinder heated in a water bath at $80^{\circ} \mathrm{C}$ for $2 \mathrm{~min}$ and pressed against the shaved rat skin for $6 \sec$ (Fig. 1A-C). Rats were then treated with alginate sponge dressing (ASDs), containing either PLGA microparticles loaded with $125 \mu \mathrm{g}$ of insulin or ASD with PLGA microparticles without insulin. These $3 \mathrm{~cm}$ in diameter dressings were placed on top of the burn wounds and covered with Tegaderm (3M, London, Canada) to keep the dressing in place over the burn (Fig. 1D,E). Dressings were replaced every 3 days and wounds cleaned with sterile saline.

Body weight (measured every two days) started from the day insulin dressings were applied and lasted until the end of healing process, did not show significant difference between placebo and insulin-treated rats (Fig. 1F). We also observed a similar physiological rhythm of changes in blood glucose in both insulin and placebo-treated rats; the levels of blood glucose decreased in from daytime to nighttime which is normal as it depends on the circadian rhythm. However, there was a significant decrease in blood glucose at 4 and $6 \mathrm{hrs}$ after insulin application, suggesting the gradual releasing of insulin from the dressing. Because in both groups and all times the blood glucose level was higher than 60mg/dl, no hypoglycemia occurred (Fig. 1G).

Insulin levels in the tissue were significantly elevated in the insulin-treated burns as seen at $12 \mathrm{hrs}$ and remained significantly elevated at 3 and 6 days post burn (each cycle of treatment), suggesting the release of insulin from the ASDs. The insulin level in placebo-treated burns stayed low until day 9 when they became elevated (Fig. 1H), suggesting the influx of insulin to aid in the later stages of burn healing.

\section{Insulin improves burn wound healing}

Insulin treatment accelerated the wound healing process only moderately as shown by a decrease in wound area when compared to placebo-treated wounds, in particular after day 9; this improvement was consistent in all of the rats we tested (Fig. 2A,B). However, histological evaluation revealed improved quality of the healing tissue. At 3 days post-burn, insulin treatment resulted in early disjunction of the epidermal layer when compared to the placebo-treated burn (Fig. 2C-F), suggesting a more rapid clearance of the dead burned tissue. Simultaneously, the granulation tissue in the insulin-treated burns was more sparse than the same tissue in the placebo, indicating faster disintegration of the collagen fibers (Fig. 2 G,H). To examine the condition of the collagen in the burn wounds we performed second harmonic generated imaging and show that insulin treatment resulted in faster dismantling of collagen fibers; the fibers in the placebo-treated burns appear thicker (Fig. 2I,J). Furthermore, insulin-treated burns showed an earlier increase in inflammatory cells (Fig. 2K,L), primarily neutrophils and M1 macrophages, cells important in clearance of bacterial load and debris, respectively (Fig. 3A\&C).

\section{Effects of insulin treatment on inflammation}

Inflammation levels in the burn wounds were assessed by quantification of inflammatory cells, specifically neutrophils and macrophages, at different time points post-burn. A significant increase in the number of neutrophils occurred during the first $12 \mathrm{hrs}$ in the insulin-treated wounds 
whereas neutrophils were not detected at that time in the placebo-treated wounds (Fig. 3A). The early recruitment of neutrophils to the site of insulin treated burns suggests a faster immune response when compared to placebo-treated burns that, in conjunction to an increase in the M1 macrophages (Fig. 3C), could be responsible for the more rapid clearance of the dead burned tissue.

The number of macrophages present in the burn wounds was determined by flow cytometry. The schematic of the analysis of macrophages with various markers is shown in Fig. 3B. Singlet cell population was defined by plotting forward scattered light height (FSC-H) vs FSC area [1,2]. The cell population was then defined with markers for M1 (CD80+, CD86+, and CD163 low) and M2 (CD163+, CD80 low, CD86 low) macrophages. The number of M1 macrophages steadily increased over time in the placebo-treated burns and at 12 days post-burn the number of M1 (pro-inflammatory) macrophages was about $3 \mathrm{X}$ higher than at day 3 , suggesting continued pro-inflammatory activity in the tissue. In contrast, the number of M1 macrophages initially rose faster in insulin-treated, becoming significantly higher by day 6, perhaps to clear the higher number of neutrophils. However, by day 9, insulin-treated burns returned to that of the placebo and by day 12, insulin treatment had significantly decreased the number of these pro-inflammatory cells (Fig. 3B,C). The pattern of M2 macrophages was distinctly different (Fig. 3B,D). At day 3 post-burn, the placebo was high and then fell off progressively through day 12 . In contrast, insulintreated burns started lower at day 3, decreased through day 9 like the placebo but then increased significantly at day 12 post-burn, suggesting that insulin induces a more anti-inflammatory environment later in healing that potentially contributes to less scarring. Because insulin stimulates an anti-inflammatory environment, we investigated the levels of interleukin-10 (IL-10), an antiinflammatory cytokine, which is known to be produced by M2 macrophages [30] as well as fibroblasts [31]. We found that, with the exception of day 6, IL-10 was significantly elevated throughout healing in insulin-treated burns than was the case with placebo-treated burns (Fig. 4). Taken together, these findings suggest that insulin treatment induces a more anti-inflammatory environment at a time in which the granulation tissue is developing (9-12 days post-burn; full wound closure occurs 22-24 days post-burn), decreasing the late inflammatory response and leading to less scarring.

\section{Insulin stimulates angiogenesis in healing of burn wounds}

The presence of new blood vessels was determined by immunolabeling the tissue sections for $\alpha$-smooth muscle actin ( $\alpha$-SMA), a protein present in the smooth muscle cells of the blood vessel walls. We observed approximately a 3 -fold increase in the number of newly formed blood vessels in insulin-treated wounds (Fig. 5A,B). However, this was not accompanied by changes in the average blood vessel width or area (Fig. 5C,D). The pro-angiogenic properties of insulin were further confirmed in a C57BL/6 mouse model by subcutaneously injecting insulin under the skin for 4 days and collecting the skin tissue to measure angiogenesis and the integrity of the blood vessels formed. Results show that insulin induced a 1.9-fold increase in the total blood vessel length, compared to placebo (Fig. 5E-G). Similarly, VE-cadherin expression was increased about 1.7-fold in the presence of insulin (Fig. 5H,I).

\section{Insulin improves collagen deposition and maturation}

Granulation tissue has collagen as the major component of the extracellular matrix (ECM). Collagen scaffold plays an intricate and important role in maintaining the biological and structural integrity of the wound tissue where both proper collagen deposition and architectural maturation 
contribute to the quality of healing. We measured hydroxyproline levels in the burn tissue to evaluate the collagen content in the granulation tissue during the course of healing and found that, when compared to placebo treatment, insulin treatment stimulates a steady increase in hydroxyproline levels after day 3 with a brief decrease at day 12 (Fig. 6A). This suggests that insulin stimulates higher deposition of collagen in the wound tissue. Indeed, we found more collagen fibers by Masson-trichrome staining (Fig. 6B) and, when using second harmonic imaging microcopy, we see that the fibers are thicker and the organization is close to the "basket-weave" pattern found in normal skin (Fig. 6C). Therefore, increases in hydroxyproline levels during the granulation tissue formation and proper maturation of collagen fibers show that insulin is able to improve the quality of the newly formed healed tissue.

\section{Insulin treatment decreases the levels of reactive oxygen species}

It is known that low levels of oxidative stress are beneficial to wound healing, whereas excessive levels are problematic for the healing process. We hypothesized that one of the mechanisms by which insulin improves burn healing is by decreasing oxidative stress early postburn. Upon injury, NADPH oxidase (NOX), acts as the primary source of superoxide anion $\left(\mathrm{O}_{2}{ }^{-}\right.$ $\cdot$ ), a highly reactive species that in the presence of superoxide dismutase (SOD) is dismutated to hydrogen peroxide $\left(\mathrm{H}_{2} \mathrm{O}_{2}\right) \cdot \mathrm{H}_{2} \mathrm{O}_{2}$, although less reactive, causes tissue damage upon accumulation and hence it is important that it be broken down to $\mathrm{H}_{2} \mathrm{O}$ and $\mathrm{O}_{2}$ or only $\mathrm{H}_{2} \mathrm{O}$ by the antioxidant enzymes catalase and glutathione peroxidase (GPx), respectively (Fig. 7A). Also, $\mathrm{H}_{2} \mathrm{O}_{2}$ in the presence of iron can enter the Fenton reaction to give rise to $\mathrm{OH}^{-}$radicals and $\mathrm{HO}^{-}$anions. Furthermore, superoxide anion, in the presence of nitric oxide (NO), produced by nitric oxide synthase (NOS), generates peroxinitrite $\left(\mathrm{ONOO}^{-}\right)$(Fig. 7A) a very reactive nitric oxide species that also causes molecular damage. We found that insulin treatment causes a decrease in SOD activity, and consequently $\mathrm{H}_{2} \mathrm{O}_{2}$ levels, during the first three days of healing (Fig. 7B, C), suggesting that insulin reduces the levels of superoxide anion generated in response to injury. Simultaneously, the levels of catalase and GPx were increased during this same period of time, contributing to the decrease in $\mathrm{H}_{2} \mathrm{O}_{2}$ levels by breaking it down to $\mathrm{H}_{2} \mathrm{O}$ and $\mathrm{O}_{2}$ or $\mathrm{H}_{2} \mathrm{O}$ respectively (Fig. 7D, E). In addition, it is well known that ROS can result in deleterious effects on lipids, proteins and DNA (Fig. 7A). Lipid peroxidation, measured by the concentration of malondialdehyde (MDA) present in the burn tissues, was similar in both insulin- and placebotreated wounds during the first 2 days post burn but decreased suddenly at day 3 in insulin-treated burns and then increased gradually over time following the curve for placebo but at a lower level (Fig. 8A). Damage to proteins, as indicated by nitrotyrosine (Fig. 8B), displays an abrupt dip at day 3 as was seen for MDA but then slowly climbs back up to the value of placebo at day 9. DNA as measured by 8-OH-dG levels (Fig. 8C), on the other hand, showed a small but significant dip at days 2-3 in insulin-treated burns but then followed the big drop at day 6 seen in the placebo, all the while staying slightly below the placebo. The insulin-induced decrease in oxidative stress this early during wound healing has powerful consequences on the subsequent healing processes in terms of inflammation, angiogenesis and scar formation.

\section{DISCUSSION}

Burn wounds are one of the leading causes of traumatic injury and death. Survivors are frequently faced with physical deformities post-healing, and often suffer from psychological 
problems. Insulin treatment resulted in an early and significantly elevated influx of neutrophils to the burn wound site during the first $12 \mathrm{hrs}$. This early increase can help contain microbial infection in the burn wounds and help in the removal of necrotic debris [32-34]. The early influx of the neutrophils may also suggests a role in the faster epidermal disjunction noted in the insulin-treated burns (Fig. 2A-D). The early disintegration of the necrotic tissue may lead to enhanced and better wound healing. The cellular and molecular mechanism(s) involved in insulin-induced early influx of neutrophils to the site of burn injury warrants further investigation. We are currently undertaking such studies and expect to report on them in the very near future.

Increase in M1 macrophages, pro-inflammatory phenotype, in insulin-treated burns suggests escalation in the host defense mechanism(s). Initial presence of M1 macrophages has been suggested to increase phagocytic activity and protect the tissue from bacterial infection and promote the removal of damaged tissue [35]. Furthermore, this increase in M1 macrophages may explain the observed early clearance of the damaged granulation tissue in insulin-treated burns. M2 macrophages have been shown to possess anti-inflammatory properties and promote angiogenesis [36,37]. Although the percentage of macrophages in the placebo burns at Day 3 was higher in comparison to insulin treatment, the M2 macrophages in insulin-treated burns significantly increased after Day 6 as compared to the placebo and was significantly higher by day 12 suggesting a potential role in the less scarring burn healing observed when the burns are treated with insulin [38].

Burn wounds cause excessive inflammation and ROS generation, hence the presence of anti-inflammatory cytokines such as IL-10 may help reduce inflammation and consequently scar formation. The IL-10 expression profile in both the placebo and insulin treated burns was biphasic as previously shown by others in burn healing [39, 40]. Our data show that insulin treatment significantly stimulates IL-10 production in both the early and the late phases. This suggests that one way insulin improves burn healing is by stimulating IL-10. Although the number of M2 macrophages, known to produce IL-10 [30], was lower in insulin-treated wounds, the source of elevated IL-10 stimulated by insulin could be due to fibroblast production [31] at both day 3 and after day 9. Fibroblast stimulation and proliferation has been shown to occur in the presence of insulin [41]. This anti-inflammatory cytokine has been shown to inhibit the activation of macrophages and the presence of reactive oxygen and nitrogen species [42-45]. The significant increase in IL-10 levels beyond day 6 in the insulin-treated burns may indicate its effects on collagen deposition and reduced scarring observed in the insulin-treated burn wounds [46-49].

An effective angiogenesis process brings nutrients and oxygen to the cells in the wound tissue, increasing their proliferation and migration [50]. We have shown that insulin has a proangiogenic effect in rats; it increases the density of newly formed microvessels in the healing tissue. For better visualization and evaluation of newly formed blood vessels, we used an in vivo mouse model with thinner skin. In agreement with our findings in the rat model, we observed an increased number of blood vessels after treatment with insulin subcutaneously. An increase in development of microvessels can help the tissue regain the state of normoxia from a state of hypoxia. Indeed, burn wound tissues have increased hypoxia and diminished oxygenation for a prolonged period of time, contributing to impaired healing. Therefore, the increased supply of oxygen and nutrients to the burn tissue stimulates better healing. 
Proper granulation tissue formation and remodeling are important to acquire the desired structural integrity post wounding. The very significant levels of hydroxyproline, a major component of collagen, in insulin-treated burns past day 6 (Fig. 6A) correlates with the increase in collagen production and deposition and basket-weave-like collagen fiber structure during the granulation tissue formation observed at day 21 (Fig. 6B), suggesting better tissue integrity.

Burn tissues are characterized by initially having high levels of oxidative stress as a result of increased formation of reactive oxygen species (ROS) that surpasses the cells' antioxidant enzymes' activity [51]. ROS such as superoxide anion and hydrogen peroxide can further react with other molecules and/or ions, forming other ROS, such as peroxynitrite when reacting with nitric oxide or hydroxyl radicals via the Fenton reaction, both of which lead to oxidative damage to most biomolecules in particular to lipids, proteins and DNA [52].

Insulin has been characterized as regulating several biological processes [53-55]. In the present study, we show that the levels of SOD activity are significantly increased in insulin-treated burn wounds shortly after burning. This suggests elevated dismutation of superoxide anions resulting in generation of $\mathrm{H}_{2} \mathrm{O}_{2}$ which is effectively removed by increased activity of both catalase and GPx in insulin-treated burns, resulting in significantly lower levels of $\mathrm{H}_{2} \mathrm{O}_{2}$, thereby indicating a decrease in oxidative stress.

In conclusion, sustained release of insulin from PLGA microparticles incorporated into alginate dressings accelerates wound healing of burns and improves the restoration of tissue integrity. This was associated with decreased initial oxidative damage, early recruitment of neutrophils, reduced damage to macromolecules and well-controlled inflammation, as well as increased angiogenesis and proper collagen deposition and maturation. The result is a completely healed tissue after 21 days post burn, with proper tissue organization, indicating that insulin, in particular when incorporated in the alginate-PLGA delivery system, may be an improved therapy for burn wounds. 


\section{REFERENCES}

1. National burn repository. Am Burn Assoc 2014, 10:1-127.

2. Gist S, Tio-Matos I, Falzgraf S, Cameron S, Beebe M: Wound care in the geriatric client. Clin Interv Aging 2009, 4:269-87.

3. Rnjak J, Ph D, Wise SG, Mithieux SM, Weiss AS: Severe Burn Injuries and the Role of Elastin in the Design of Dermal Substitutes. Tissue Eng 2011, 17:81-91.

4. Nguyen JQ, Crouzet C, Mai T, Riola K, Uchitel D, Liaw L-H, Bernal N, Ponticorvo A, Choi B, Durkin AJ: Spatial frequency domain imaging of burn wounds in a preclinical model of graded burn severity. $J$ Biomed Opt 2013, 18:1-8.

5. Norbury WB, Jeschke MG, Herndon DN: Metabolic Changes Following Major Burn Injury : How to Improve Outcome. Intensive Care Emerg Med 2006.

6. Cuthbetrson D: Post-shock metabolic response*1. Lancet 1942, 239:433-437.

7. Hart DW, Wolf SE, Mlcak R, Chinkes DL, Ramzy PI, Obeng MK, Ferrando AA, Wolfe RR, Herndon DN: Persistence of muscle catabolism after severe burn. Surgery 2000, 128:312-9.

8. Gauglitz GG, Herndon DN, Jeschke MG: Insulin resistance postburn: underlying mechanisms and current therapeutic strategies. J Burn Care Res , 29:683-94.

9. Herndon DN, Tompkins RG: Support of the metabolic response to burn injury. Lancet 2004, 363:1895-902.

10. Sahib AS, Al-Jawad FH, Al-Kaisy AA: Burns, endothelial dysfunction, and oxidative stress: the role of antioxidants. Ann Burns Fire Disasters 2009, 22:6-11.

11. Pidcoke HF, Wade CE, Wolf SE: Insulin and the burned patient. Crit Care Med 2007, 35(9 Suppl):S524-30.

12. Joseph B: Insulin in the Treatment of Non-Diabetic Bed Sores. Ann Surg 1930, 92:318319.

13. Van Ort SR, Gerber RM: Topical application of insulin in the treatment of decubitus ulcers: a pilot study. Nurs Res , 25:9-12.

14. Liu Y, Zhang X, Zhang Z, Fang P-Y, Xu W-S: [Effects of topical application of insulin on the wound healing in scalded rats]. Zhonghua Shao Shang Za Zhi 2004, 20:98-101.

15. Zhang XJ, Wu X, Wolf SE, Hawkins HK, Chinkes DL, Wolfe RR: Local Insulin-Zinc Injection Accelerates Skin Donor Site Wound Healing. J Surg Res 2007, 142:90-96. 
16. Ferrando AA, Chinkes DL, Wolf SE, Matin S, Herndon DN, Wolfe RR: A submaximal dose of insulin promotes net skeletal muscle protein synthesis in patients with severe burns. Ann Surg 1999, 229:11-8.

17. Kwon Y-B, Kim H-W, Roh D-H, Yoon S-Y, Baek R-M, Kim J-Y, Kweon H, Lee K-G, Park Y-H, Lee J-H: Topical application of epidermal growth factor accelerates wound healing by myofibroblast proliferation and collagen synthesis in rat. $J$ Vet Sci 2006, 7:105-9.

18. Wang X-J, Han G, Owens P, Siddiqui Y, Li AG: Role of TGF beta-mediated inflammation in cutaneous wound healing. J Investig Dermatol Symp Proc 2006, 11:112-7.

19. Demling RH: The role of anabolic hormones for wound healing in catabolic states. $J$ Burns Wounds 2005, 4:e2.

20. Bitto A, Minutoli L, Altavilla D, Polito F, Fiumara T, Marini H, Galeano M, Calò M, Lo Cascio P, Bonaiuto M, Migliorato A, Caputi AP, Squadrito F: Simvastatin enhances VEGF production and ameliorates impaired wound healing in experimental diabetes. Pharmacol Res 2008, 57:159-69.

21. Mohammadi AA, Bakhshaeekia A, Alibeigi P, Hasheminasab MJ, Tolide-ei HR, Tavakkolian AR, Mohammadi MK: Efficacy of propranolol in wound healing for hospitalized burn patients. J Burn Care Res , 30:1013-7.

22. Hrynyk M, Martins-Green M, Barron AE, Neufeld RJ: Alginate-PEG sponge architecture and role in the design of insulin release dressings. Biomacromolecules 2012, 13:1478-85.

23. Ehrenreich M, Ruszczak Z: Tissue-engineered temporary wound coverings. Important options for the clinician. Acta Dermatovenerol APA 2006, 15.

24. Lee KY, Mooney DJ: Alginate: properties and biomedical applications. Prog Polym Sci 2012, 37:106-126.

25. Mogoşanu GD, Grumezescu AM. Natural and synthetic polymers for wounds and burns dressing. Int J Pharm 2014, 463:127-36.

26. Dantas MDM, Cavalcante DRR, Araújo FEN, Barretto SR, Aciole GTS, Pinheiro a LB, Ribeiro M a G, Lima-Verde IB, Melo CM, Cardoso JC, Albuquerque Júnior RLC:

Improvement of dermal burn healing by combining sodium alginate/chitosan-based films and low level laser therapy. J Photochem Photobiol B 2011, 105:51-9.

27. Hrynyk M, Martins-Green M, Barron AE, Neufeld RJ: Sustained prolonged topical delivery of bioactive human insulin for potential treatment of cutaneous wounds. Int $J$ Pharm 2010, 398:146-54. 
28. Dhall S, Do DC, Garcia M, Kim J, Mirebrahim S, Lonardi S, Nothnagel EA, Schiller N, Martins-Green M: Generating and Reversing Chronic Wounds in Diabetic Mice by Manipulating Wound Redox Parameters. J Diabetes Res 2014.

29. Dhall S, Do D, Garcia M, Wijesinghe DS, Brandon A, Kim J, Sanchez A, Lyubovitsky J, Gallagher S, Nothnagel EA, Chalfant CE, Patel RP, Schiller N, Martins-Green M: A novel model of chronic wounds: importance of redox imbalance and biofilm-forming bacteria for establishment of chronicity. PLoS One 2014, 9:e109848.

30. Da Silva MD, Bobinski F, Sato KL, Kolker SJ, Sluka K a., Santos ARS: IL-10 Cytokine Released from M2 Macrophages Is Crucial for Analgesic and Anti-infiammatory Effects of Acupuncture in a Model of Inflammatory Muscle Pain. Mol Neurobiol 2014, 10:19-31.

31. Ina K, Kusugami K, Kawano Y, Nishiwaki T, Wen Z, Musso A, West G a, Ohta M, Goto H, Fiocchi C: Intestinal fibroblast-derived IL-10 increases survival of mucosal $\mathbf{T}$ cells by inhibiting growth factor deprivation- and Fas-mediated apoptosis. $J$ Immunol 2005, 175:2000-2009.

32. Nathan C: Neutrophils and immunity: challenges and opportunities. Nat Rev Immunol 2006, 6:173-82.

33. Fielding R a, Manfredi TJ, Ding W, Fiatarone M a, Evans WJ, Cannon JG: Acute phase response in exercise. III. Neutrophil and IL-1 beta accumulation in skeletal muscle. Am J Physiol 1993, 265(1 Pt 2):R166-R172.

34. Teixeira CF., Zamuner S., Zuliani J., Fernandes C., Cruz-Hofling M., Fernandes I, Chaves F, Gutierrez J.: Neutrophils Do Not Contribute To Local Tissue Damage, But Play a Key Role in Skeletal Muscle Regeneration, in Mice. Muscle Nerve 2003:449-459.

35. Ferrante CJ, Leibovich SJ: Regulation of Macrophage Polarization and Wound Healing. Adv wound care 2012, 1:10-16.

36. Gordon S: Alternative activation of macrophages. Nat Rev Immunol 2003, 3:23-35.

37. Jetten N, Verbruggen S, Gijbels MJ, Post MJ, De Winther MPJ, Donners MMPC: Antiinflammatory M2, but not pro-inflammatory M1 macrophages promote angiogenesis in vivo. Angiogenesis 2014, 17:109-18.

38. Sindrilaru A, Peters T, Wieschalka S, Baican C, Baican A, Peter H, Hainzl A, Schatz S, Qi Y, Schlecht A, Weiss JM, Wlaschek M, Sunderkötter C, Scharffetter-kochanek K: An unrestrained proinflammatory M1 macrophage population induced by iron impairs wound healing in humans and mice. 2011, 121:985-997.

39. Gauglitz GG, Song J, Herndon DN, Finnerty CC, Boehning D, Barral JM, Jeschke MG: Characterization of the inflammatory response during acute and post-acute phases after severe burn. Shock 2008, 30:503-507. 
40. Finnerty CC, Przkora R, Herndon DN, Jeschke MG: Cytokine expression profile over time in burned mice. Cytokine 2009, 45:20-5.

41. Monaco S, Illario M, Rusciano MR, Gragnaniello G, Di Spigna G, Leggiero E, Pastore L, Fenzi G, Rossi G, Vitale M: Insulin stimulates fibroblast proliferation through calciumcalmodulin-dependent kinase II. Cell Cycle 2009, 8:2024-2030.

42. Gazzinelli RT, Oswald IP, James SL, Sher a: IL-10 inhibits parasite killing and nitrogen oxide production by IFN-gamma-activated macrophages. J Immunol 1992, 148:1792-1796.

43. Bogdan BC, Vodovotz Y, Nathan C: Macrophage deactivation by Interleukin 10. J Exp 1991, 174(December):1549-1555.

44. Fiorentino DF, Zlotnik A, Mosmann TR, Howard M, O'Garra A: IL-10 inhibits cytokine production by activated macrophages. $J$ Immunol 1991, 147:3815-22.

45. Thompson K, Maltby J, Fallowfield J, McAulay M, Millward-Sadler H, Sheron N:

Interleukin-10 expression and function in experimental murine liver inflammation and fibrosis. Hepatology 1998, 28:1597-1606.

46. Finnegan A, Kaplan CD, Cao Y, Eibel H, Glant TT, Zhang J: Collagen-induced arthritis is exacerbated in IL-10-deficient mice. Arthritis Res Ther 2003, 5:R18-R24.

47. Henningsson L, Eneljung T, Jirholt P, Tengvall S, Lidberg U, van den Berg WB, van de Loo F a., Gjertsson I: Disease-Dependent Local IL-10 Production Ameliorates Collagen Induced Arthritis in Mice. PLoS One 2012, 7:1-8.

48. Kieran I, Knock A, Bush J, So K, Metcalfe A, Hobson R, Mason T, O’Kane S, Ferguson M: Interleukin-10 reduces scar formation in both animal and human cutaneous wounds: results of two preclinical and phase II randomized control studies. Wound Repair Regen 2013, 21:428-36.

49. King A, Balaji S, Le LD, Crombleholme TM, Keswani SG: Regenerative Wound Healing: The Role of Interleukin-10. Adv wound care 2014, 3:315-323.

50. Tonnesen MG, Feng X, Clark R a: Angiogenesis in wound healing. $J$ Investig Dermatol Symp Proc 2000, 5:40-6

51. Parihar A, Parihar MS, Milner S, Bhat S: Oxidative stress and anti-oxidative mobilization in burn injury. Burns 2008, 34:6-17.

52. Salvemini D, Doyle TM, Cuzzocrea S: Superoxide, peroxynitrite and oxidative/nitrative stress in inflammation. Biochem Soc Trans 2006, 34(Pt 5):965-70.

53. Wilcox G: Insulin and insulin resistance. Clin Biochem Rev 2005, 26:19-39. 
54. Harmancey R, Lam TN, Lubrano GM, Guthrie PH, Vela D, Taegtmeyer H: Insulin resistance improves metabolic and contractile efficiency in stressed rat heart. FASEB $J$ 2012, 26:3118-26.

55. Weissman C: The Metabolic Response to Stress.pdf. Anesthisiology 1990, 73:308-327. 


\section{CLINICAL PERSPECTIVES}

A short outline highlighting the clinical significance of the paper within approximately $100-150$ words (about three sentences) should be provided. This section should (i) provide some background as to why the study was undertaken, (ii) provide a brief summary of the results and then (iii) indicate the potential significance of the results to human health and disease.

(i) The study was undertaken to investigate the efficacy of sustained release of insulin from PLGA microparticles embedded in alginate gels in burn wound healing and to understand the mechanism of the accelerated healing observed in insulin treated burns.

(ii) Our findings show that sustained release of insulin from PLGA microparticles lead to accelerated healing via decrease in oxidative stress and tissue damage, early recruitment of neutrophils, management of inflammatory cells, enhanced angiogenesis, and proper collagen deposition and maturation.

(iii) Use of sustained release of insulin in a moist environment in burn wounds could result in faster and improved healing outcomes.

\section{AUTHOR CONTRIBUTION}

Conceived and designed the experiments: SD JPS YL, MH, RJN, MMG. Performed the experiments: SD JPS YL MH MG JL MMG. Analyzed the data: SD JPS YL AC MMG Contributed reagents/materials/analysis tools: MMG, RJN, MH, JL. Wrote the paper: SD JPS MMG.

\section{ACKNOWLEDGEMENTS}

We thank the Genomics core facility and the Stem Cell Center core facility at the University of California, Riverside for the use of FACS Aria and Luminex 200 respectively. We thank Dr. Julia Lyubovitsky for her help with second harmonic generated imaging.

\section{FUNDING}

This work was supported by funds from National Natural Science Fund of China [81170761] and [81270909] to YL, the Natural Sciences and Engineering Research Council of Canada for research funding and for postgraduate scholarship to $\mathrm{MH}$ and by a gift to MMG. 


\section{FIGURE LEGENDS}

Figure 1. Partial thickness burn wound model system: (A) Hair was removed from the back of Sprague-Dawley rats by use of 'Nair'. (B) Brass metal at $80^{\circ} \mathrm{C}$ was used to create (C) identical burns at the shaved site. (D) Insulin-loaded alginate sponge dressing was wetted with $100 \mu 1$ of sterile water. (E) Sponge dressing was placed on the site of burn injury and covered with a transparent Tegaderm film. Dressing was changed every three days. (F) Change in body weight over time was measured every 2 days post-burn. (G) Level of blood glucose was measured using an electronic glucose meter every two hours post-burn. (H) Insulin levels in the burn tissue were measured using a sandwich ELISA, and the levels were detected at $450 \mathrm{~nm}$. All data are Mean \pm SD. $n=6 * * p<0.01, * * * p<0.001$.

Figure 2. Insulin-treated burns show improved healing: (A) Enhanced wound closure was observed in insulin-treated rats when compared to the placebo-treated group. Scale bar $=5 \mathrm{~mm}$ (B) Percent wound closure over time was evaluated by tracing wounds using ImageJ. (C-J) Histological evaluation of placebo- and insulin-treated burn wound sections at Day 3 post-burn was done by staining with Hemotoxylin and Eosin. Insulin-treated burns showed early epidermal disjunction $(\mathbf{C}-\mathbf{F})$ Scale bar $=100 \mu \mathrm{m}$, less compact granulation tissue $(\mathbf{G}, \mathbf{H})$ Scale bar $=100 \mu \mathrm{m}$. Second harmonic imaging microscopy of burn tissue at Day 3 showed increased fraying of the collagen fibrillar structure in insulin-treated burns. (I,J) Scale bar $=10 \mu \mathrm{m}$. Enhanced recruitment of inflammatory cells in insulin-treated burns $(\mathbf{K}, \mathbf{L})$ Scale bar $=100 \mu \mathrm{m}$. All data are Mean $\pm S D$. $n=6 * * p<0.01, * * * p<0.001$.

Figure 3. Insulin-treated burns show early and improved inflammatory response: (A) Burn wound sections were immunolabeled with antibodies against myeloperoxidase (MPO), a neutrophil marker. Early induction of neutrophils was seen in insulin-treated burns at $12 \mathrm{hrs}$ post burn. The number of neutrophils was counted for 10 fields. (B) Schematic of flow cytometry analysis of single cells isolated from placebo- and insulin-treated burns at various time points. $[1,2,3]$ SSC-A is Side scatter area, FSC-H is Forward scatter Height and FSC-A is Forward scatter area. [4] FACS was performed on burn wound cells immunolabeled with CD80- PE, CD86- FITC and CD163-APC. [5] Cells that are CD163+, CD80 low and CD86 low are of M2 macrophage phenotype. [6] Cells that are CD80+, CD86+ and CD163 low are of M1 macrophage phenotype. Percent macrophages calculation shown in [5] and [6] are based on the parent population in [4]. (C) Percentage of M1 macrophage phenotype cells were calculated based on the total cell population using the markers CD80+, CD86+ and CD163 low (D) Percentage of M2 macrophage phenotype cells were calculated based on the total cell population using the markers CD80low, CD86low and CD163+. All data are Mean $\pm S D .{ }^{*} p<0.05,{ }^{* *} p<0.01 . n=5$ in 3 different experiments.

Figure 4. Interleukin-10 (IL-10) levels are elevated in insulin-treated burns: Burn wound tissue homogenate was used to quantify the levels using a cytokine immunoassay. Levels of IL-10 were quantified using a LuminexTM 200 instrument by monitoring the fluorescence associated with the magnetic bead set. All data are Mean $\pm S D$. ${ }^{*} p<0.05,{ }^{* *} p<0.01,{ }^{* * *} p<0.001$.

Figure 5. Insulin-treated burns show increased angiogenesis and improved permeability of blood vessels: (A) Burn wound sections were stained with $\alpha$ smooth muscle actin ( $\alpha$ SMA), for 
pericytes/smooth muscle cells lining blood vessels at Day 9 post burn. (B,C,D) The area and width of the blood vessels were calculated using ImageJ. The number of blood vessels was counted for 10 fields. (E,F, G) Stimulation of angiogenesis upon insulin treatment was done by subcutaneous injection of $1 \mu \mathrm{g}$ insulin and PBS independently for 4 days, followed by excision of the area of interest and counting the length of blood vessels. (H, I) Immunoblot analysis and quantification of VE cadherin levels was done to support the data in $\mathrm{H}$ and I. Data shown are representative of 3 blots. Figure E-I were done in mice. All data are Mean $\pm S D .{ }^{*} p<0.05,{ }^{* *} p<0.01,{ }^{* * *} p<0.001$.

Figure 6. Collagen deposition is increased and more mature in insulin-treated burns: (A) Hydroxyproline estimation, major component of collagen and roles in collagen stability, was done by chromogen production that was read at an absorbance maximum at $560 \mathrm{~nm}$. (B) Day 21 post burn tissue treated with insulin or placebo were sectioned and stained with Masson trichrome, that stains the nuclei dark with Weigert's hematoxylin, the cytoplasm and muscle fibers red with Biebrich scarlet dye, and the collagen blue with analine blue dye. (C) Second harmonic imaging microscopy of the burns at Day 21, shows better 'basket weave' like structures in insulin-treated burn as compared to the placebo-treated group. Data in A are Mean $\pm S D . n=5{ }^{*} p<0.05$, ${ }^{* *} p<0.01,{ }^{* * *} p<0.001$

Figure 7. Regulation of redox state is enhanced in insulin-treated burns: (A) Schematic representing redox mechanism of production of reactive oxygen species and their detoxification by catalase and glutathione peroxidase enzymes. (B) Superoxide dismutase (SOD) activity was measured using tetrazolium salt that is detectible at $450 \mathrm{~nm}$ upon conversion into formazan dye. One unit of SOD is defined as the amount of enzyme needed to cause $50 \%$ dismutation of the superoxide radical. (C) $\mathrm{H}_{2} \mathrm{O}_{2}$ was measured using a non-fluorescent substrate 10-acetyl-3,7dihydroxyphenoxazine that converts to fluoroscent substance, resofurin, detectible at $530 \mathrm{~nm} / 605 \mathrm{~nm}$. (D) Catalase activity was measured spectrophotometrically using chromogen purpald at $540 \mathrm{~nm}$. Catalase and methanol react to give rise to formaldehyde that further reacts with the chromogen. (E) Glutathione peroxidase activity was measured using a kinetic reactive measurement where glutathione peroxidase is the limiting reagent. Absorbance was read at $340 \mathrm{~nm}$ at $1 \mathrm{~min}$ intervals. Overall, oxidative stress was reduced in insulin treated burns. All data are Mean \pm SD. $n=5 * p<0.05, * * p<0.01, * * * p<0.001$.

Figure 8. Damage to lipids, proteins and DNA is reduced in insulin-treated burns : (A) Lipid peroxidation levels were fluorometrically measured at an Ex/Em of $540 \mathrm{~nm} / 590 \mathrm{~nm}$ using thiobarbituric acid reactive substances (TBARS). (B) Nitrotyrosine levels were evaluated using a competitive enzyme immunoassay. (C) $8-\mathrm{OHdG}$ levels were read spectrophotometrically at $412 \mathrm{~nm}$ using Ellman's reagent. Damage caused by oxidative stress was ameliorated in the insulintreated burns. All data are Mean $\pm S D . n=5{ }^{*} p<0.05,{ }^{* *} p<0.01$.

\section{SUMMARY STATEMENT}

Bioactive crystalline insulin microencapsulated in a FDA-approved copolymeric substance (poly\{lactic-co-glycolic acid\}), when released in a sustained manner to burn wounds, stimulated improved healing by reducing stress-related tissue damage, controlling inflammation, and enhancing tissue integrity. 

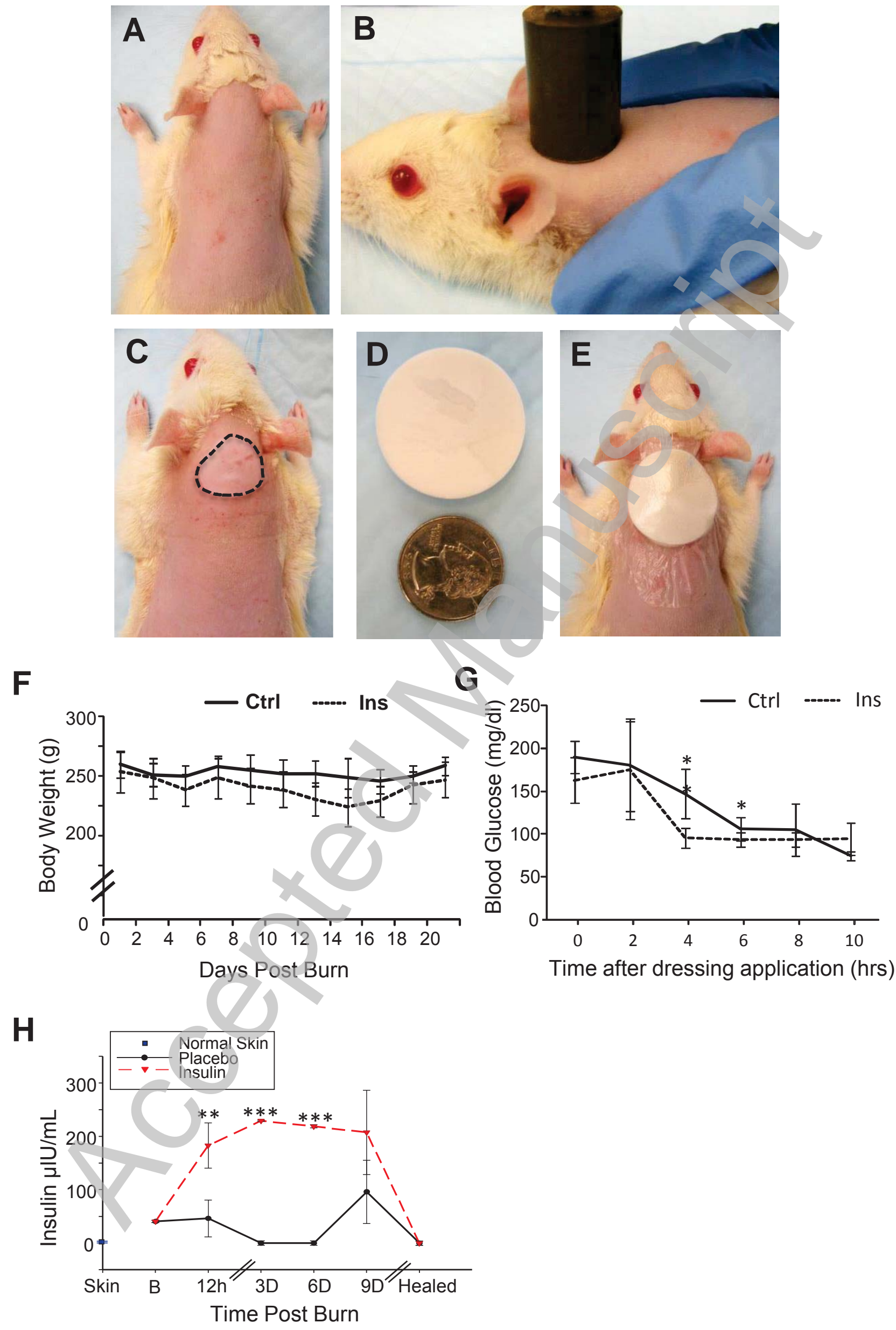

Figure 1 
A Placebo Insulin
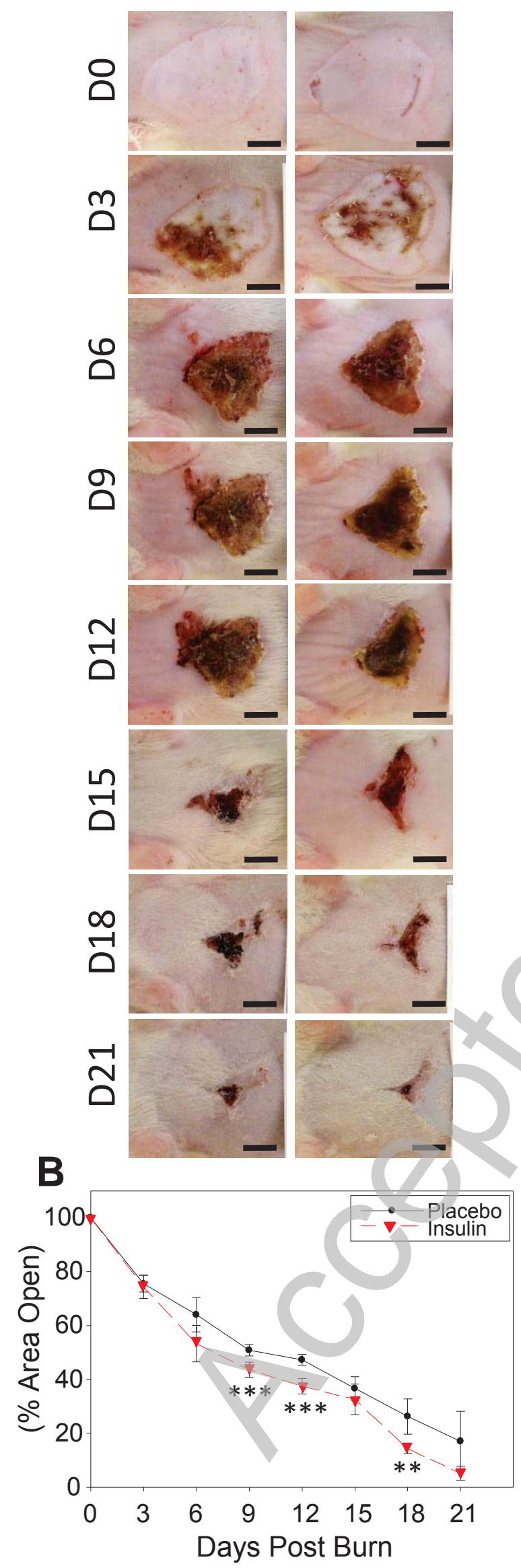

Placebo
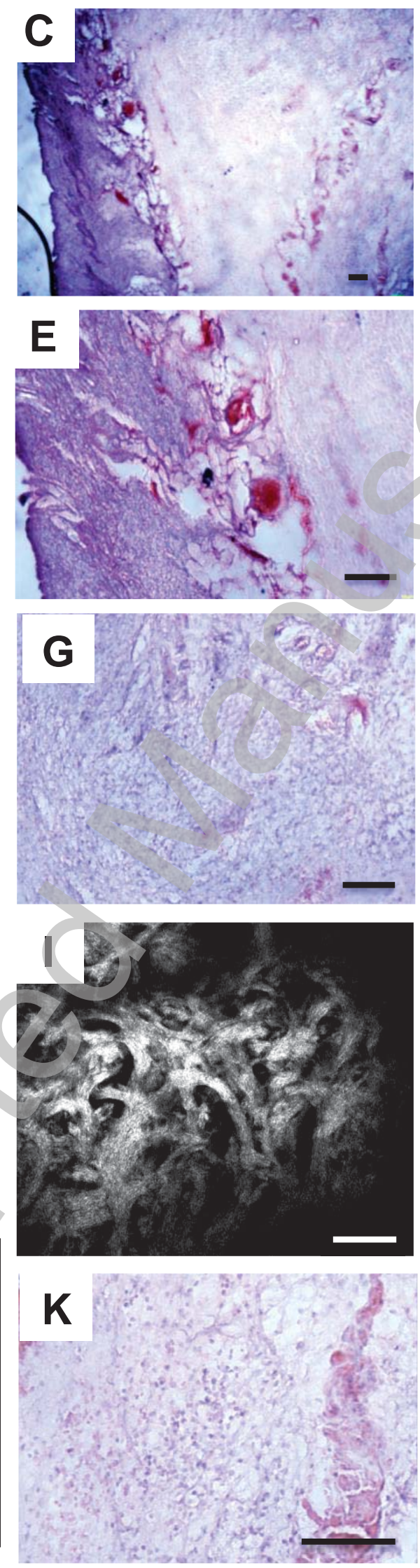

Insulin
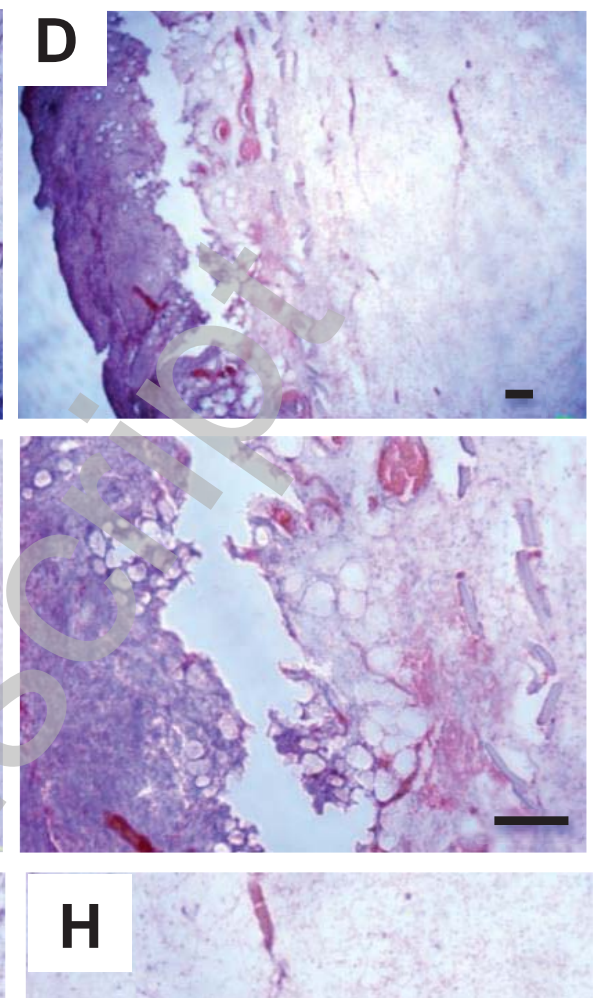
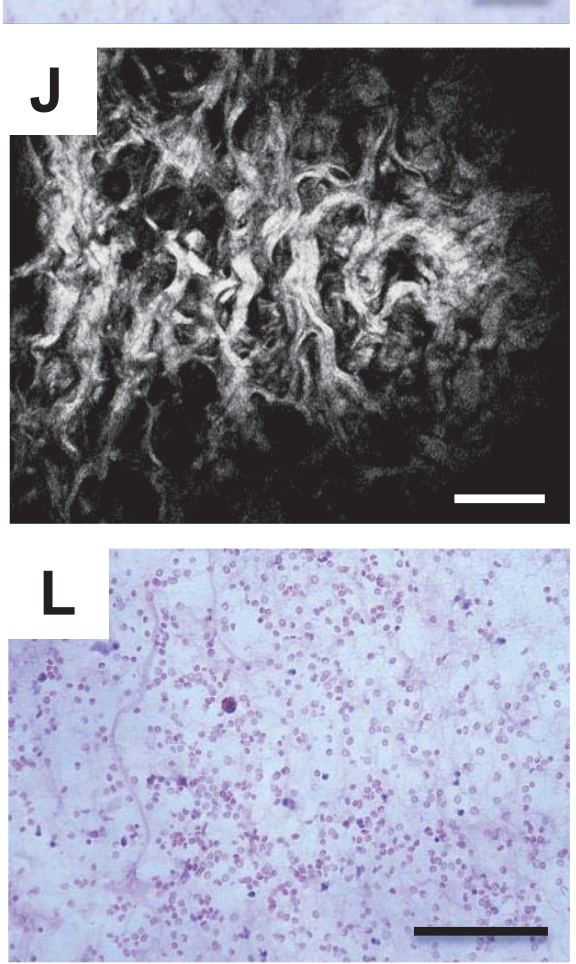


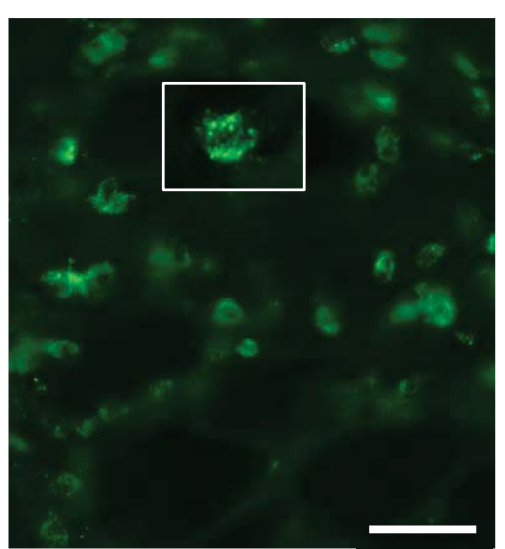

Green - Myeloperoxidase

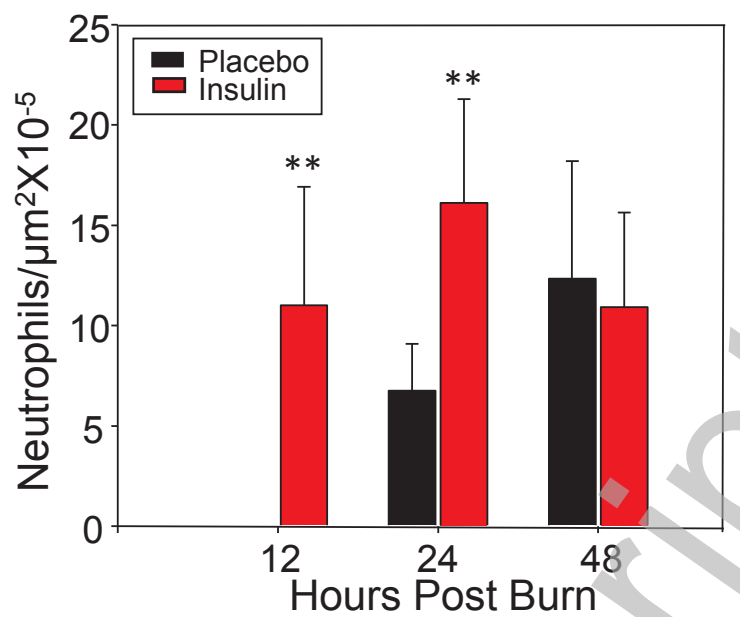

B
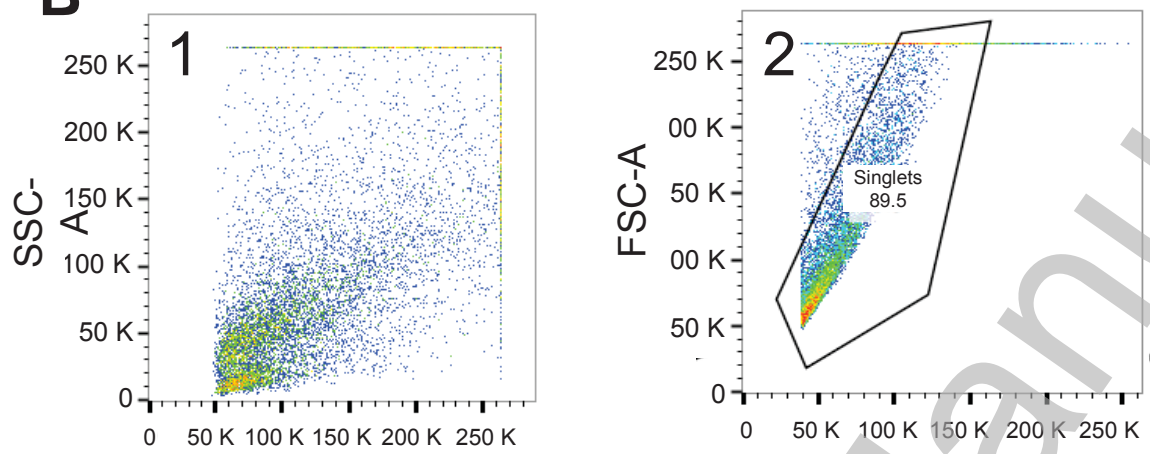

FSC-A
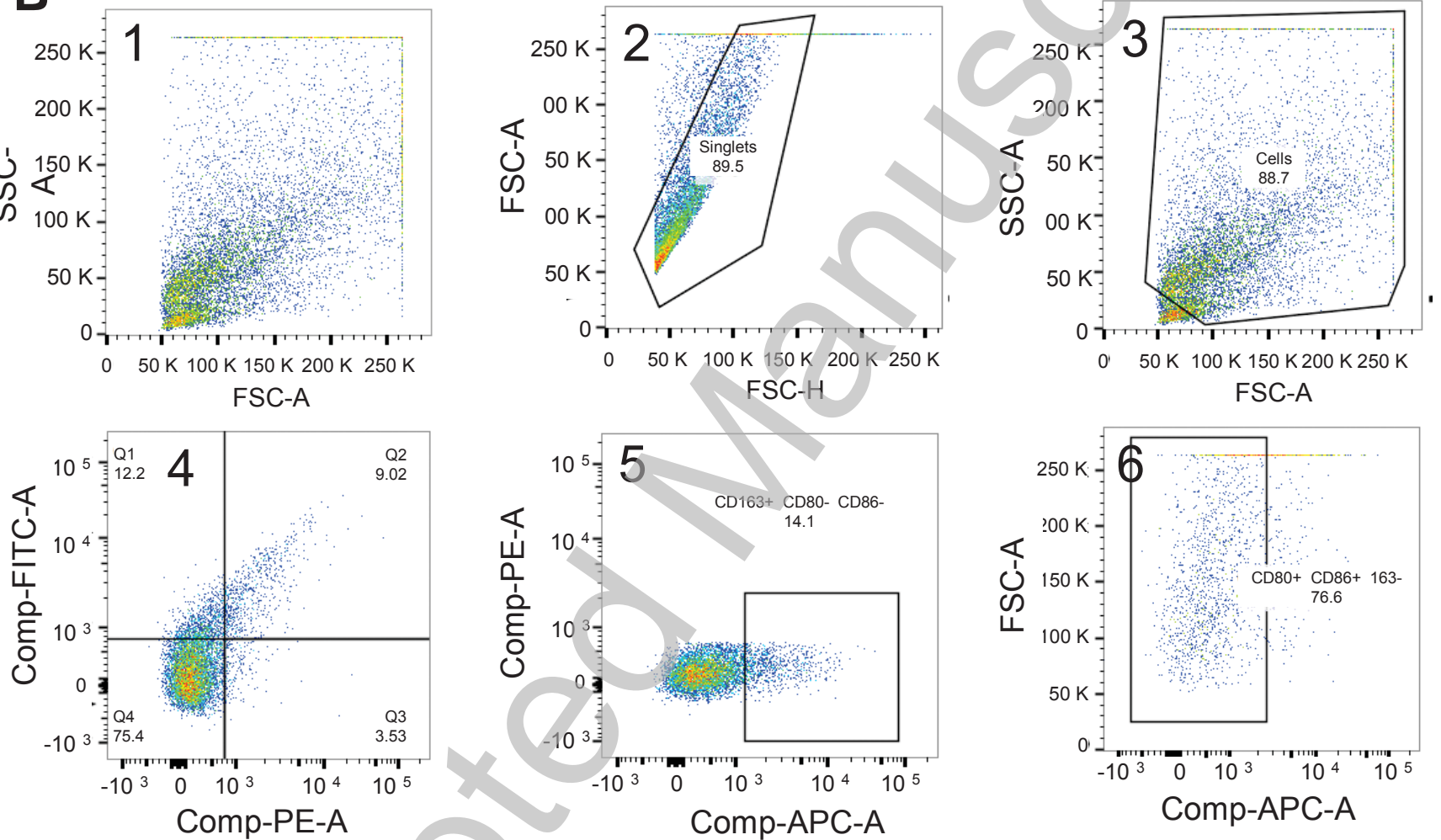

FSC-H

FSC-A

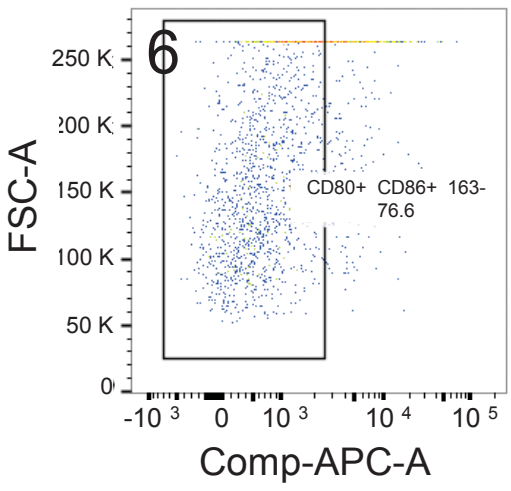

C

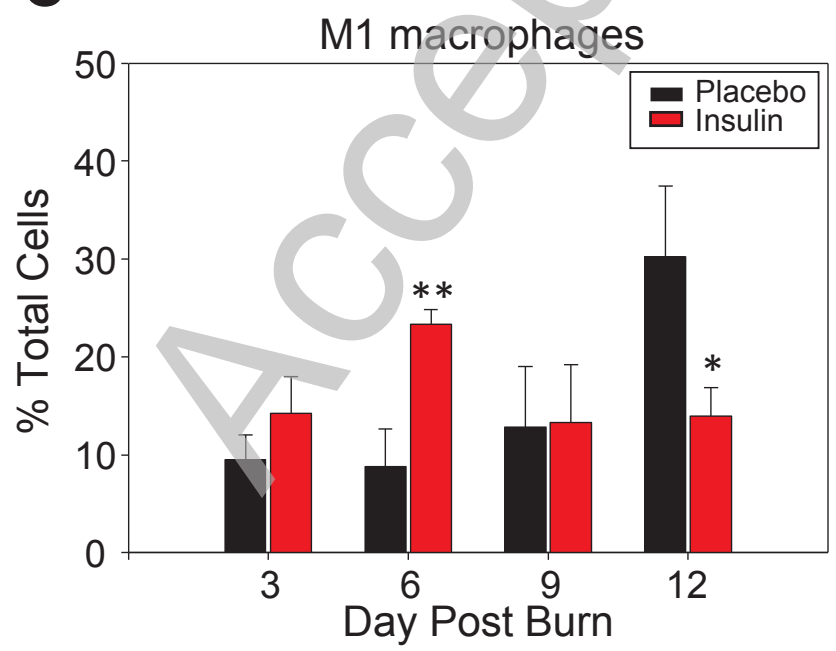

D

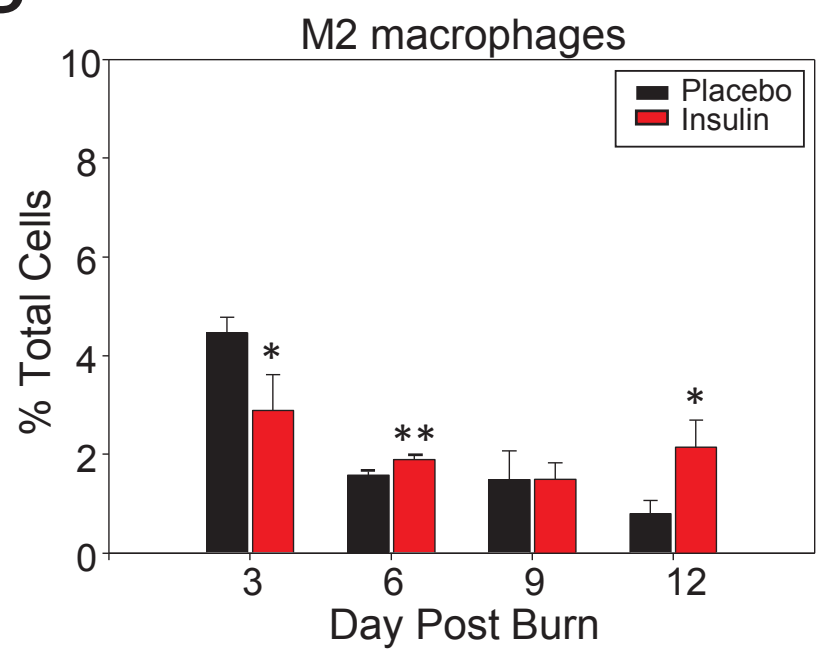

Figure 3 


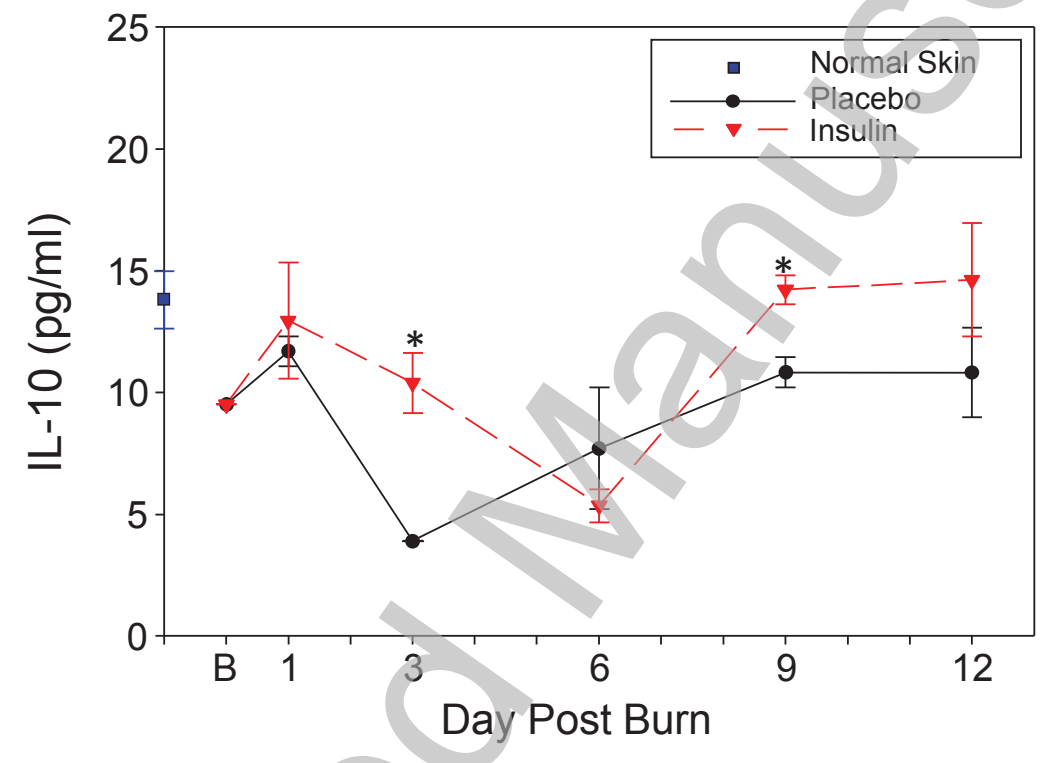

Figure 4 

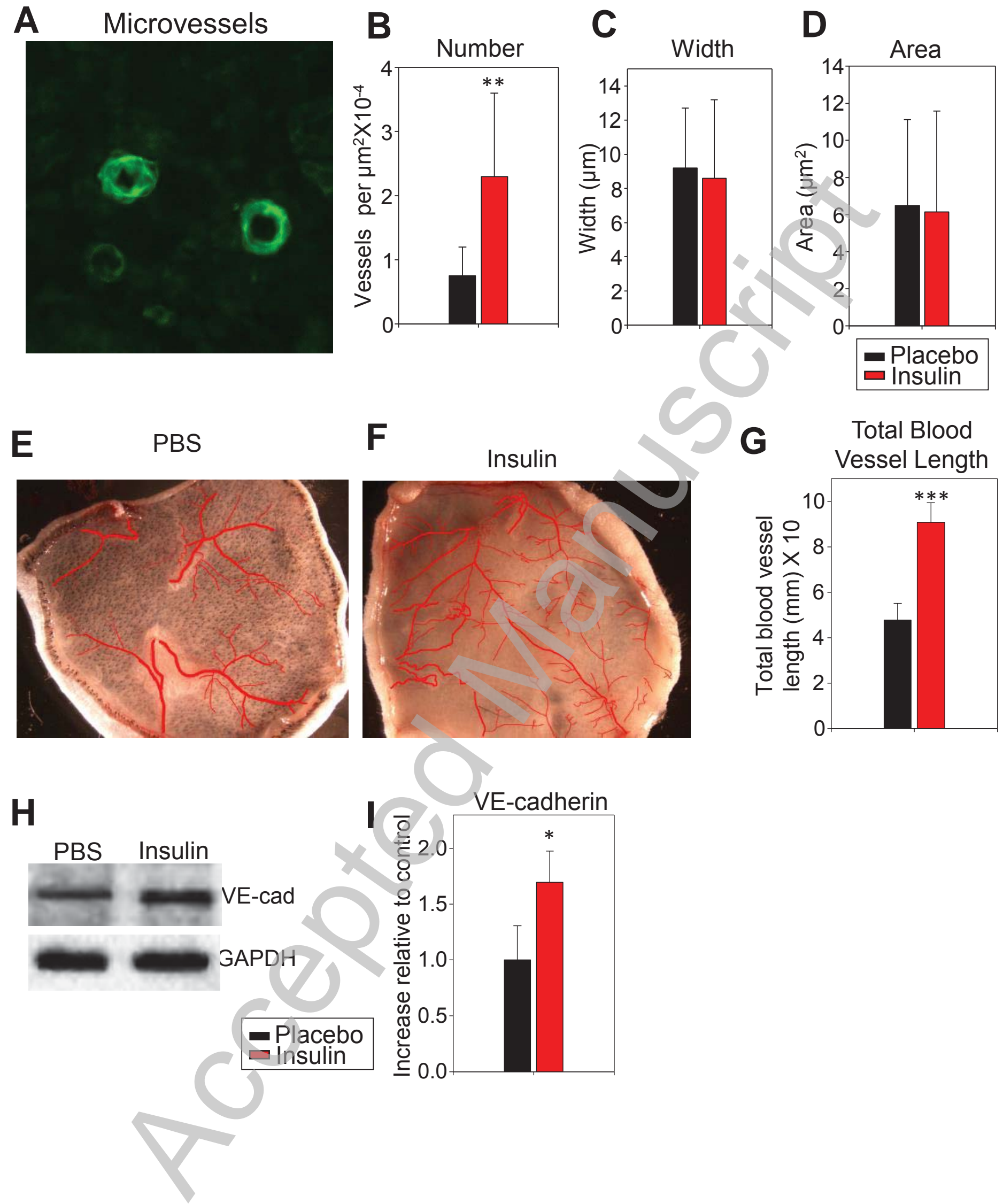

Figure 5 
A
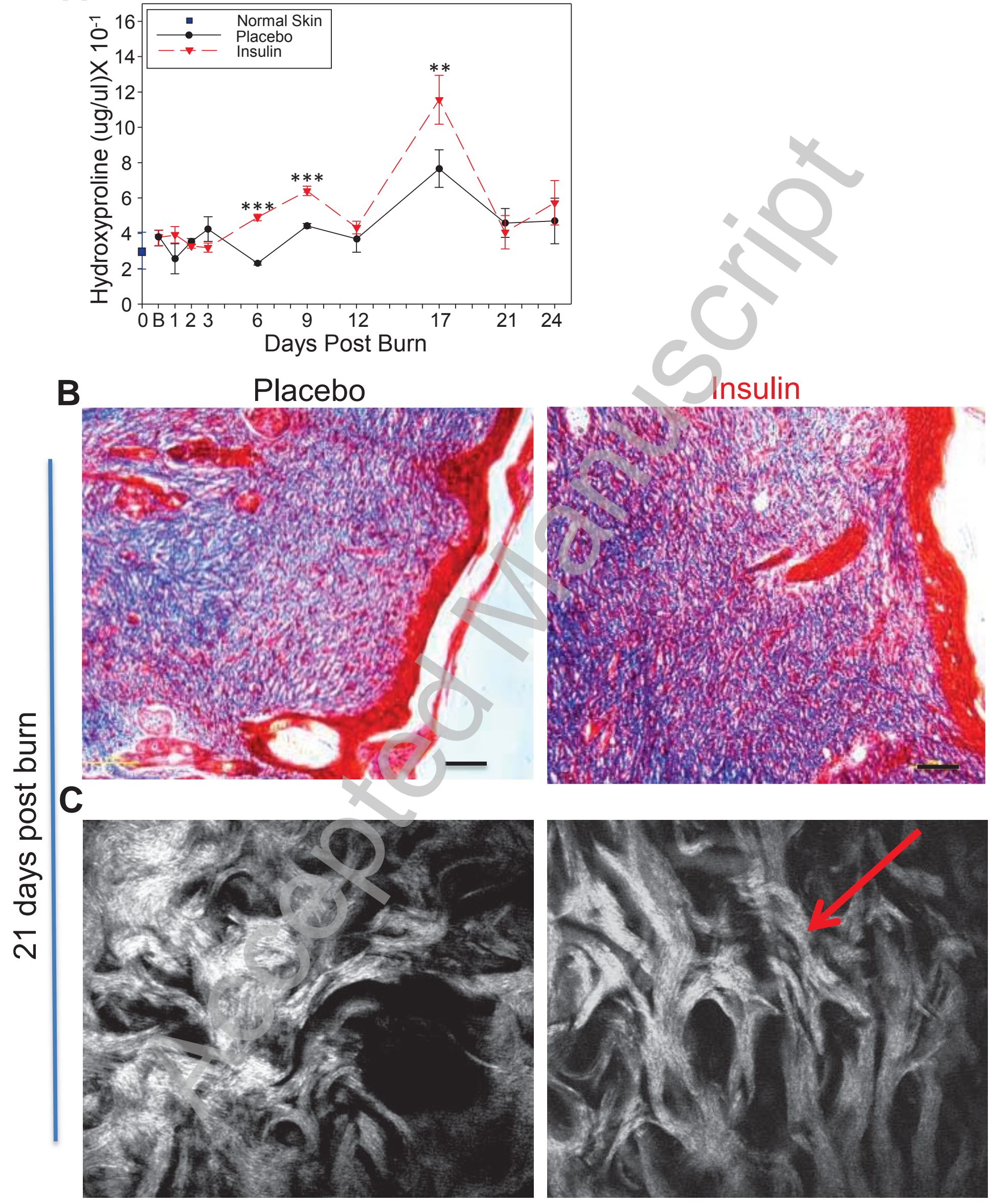

Figure 6 
A
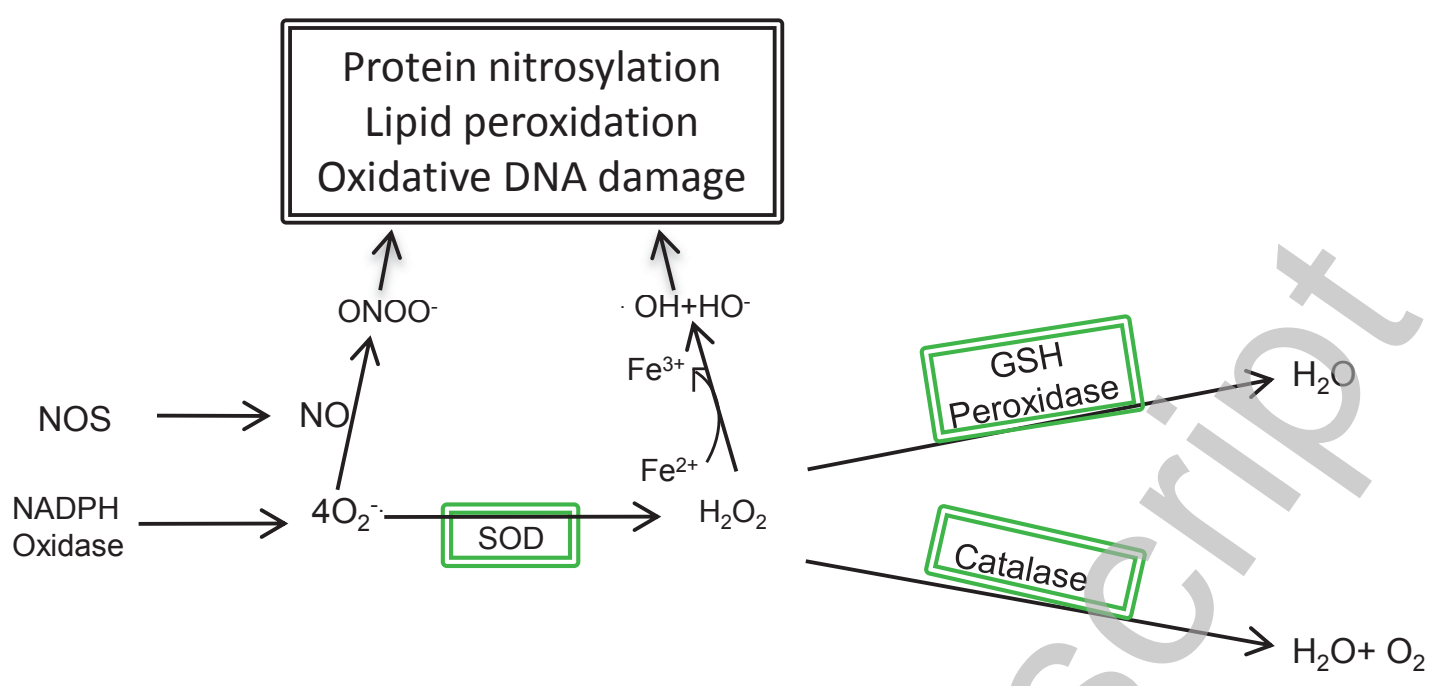

B
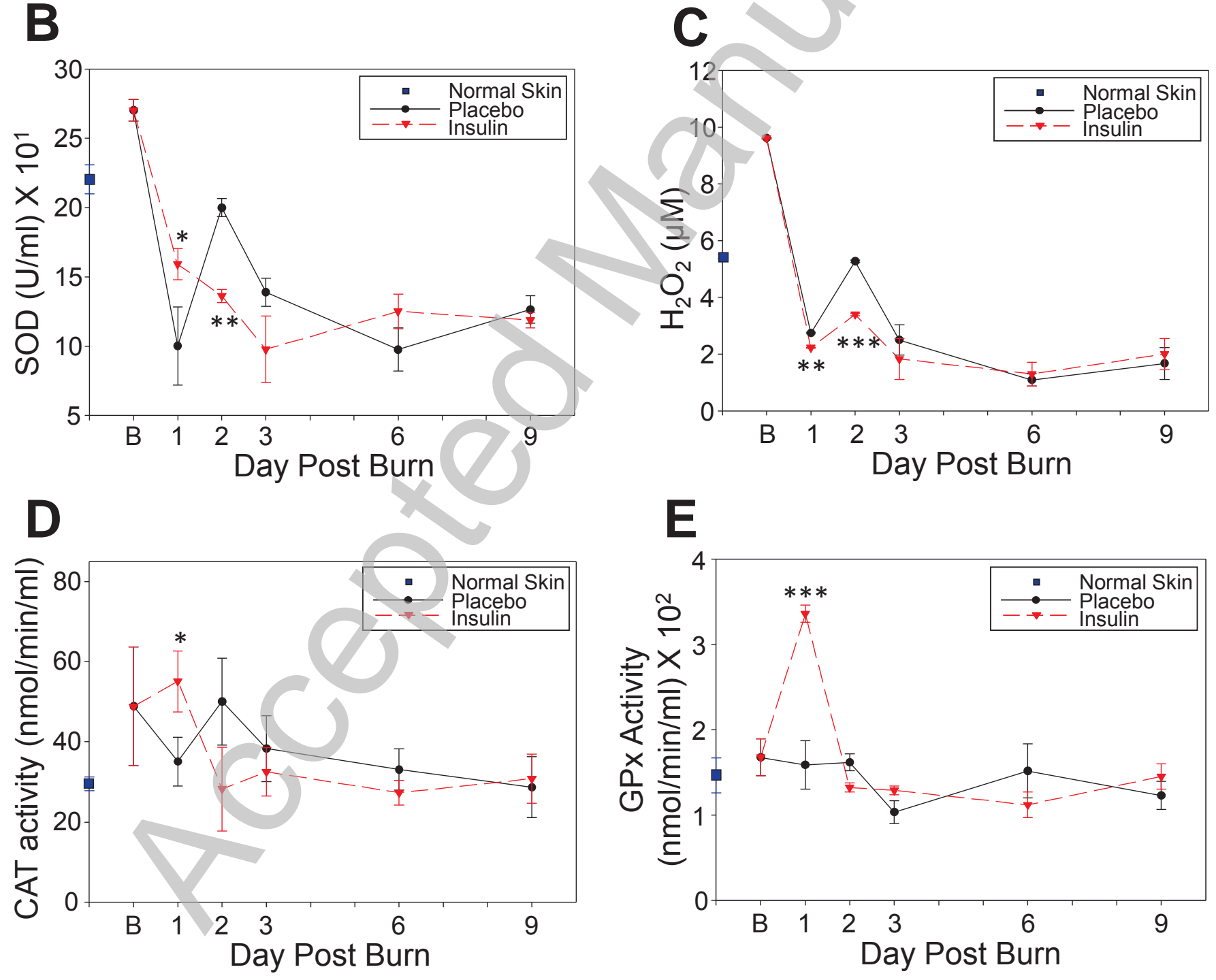

Figure 7 


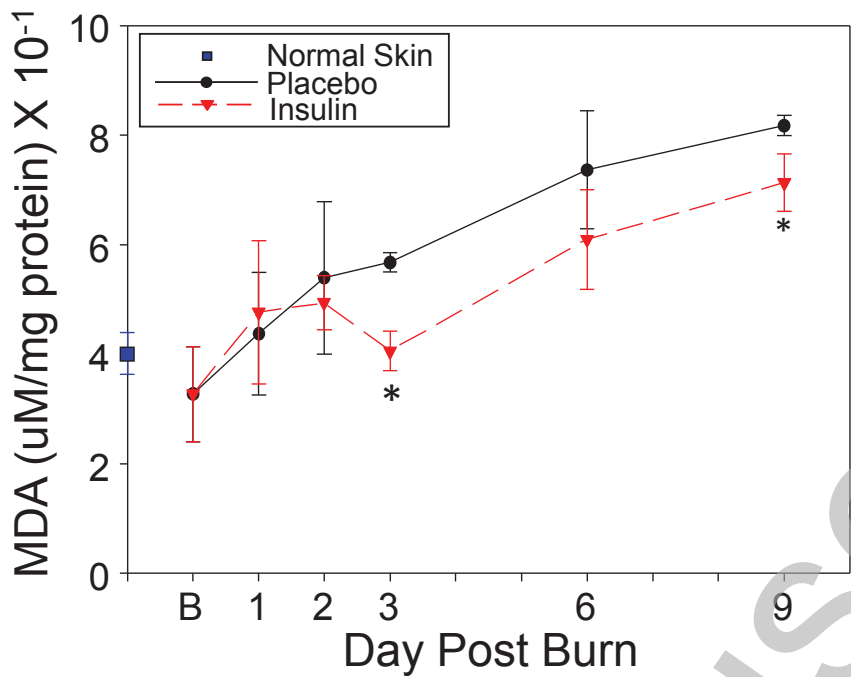

B

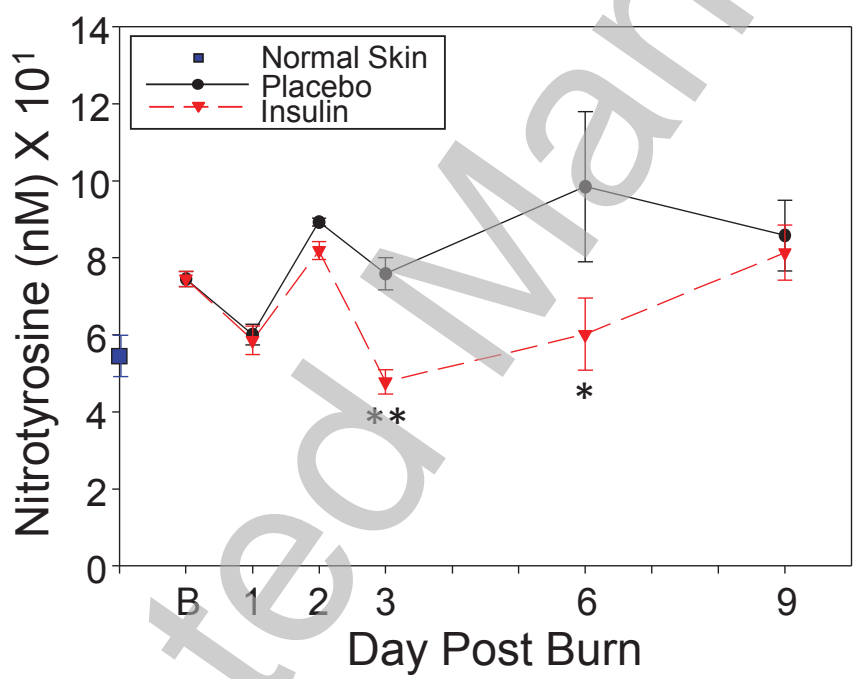

C

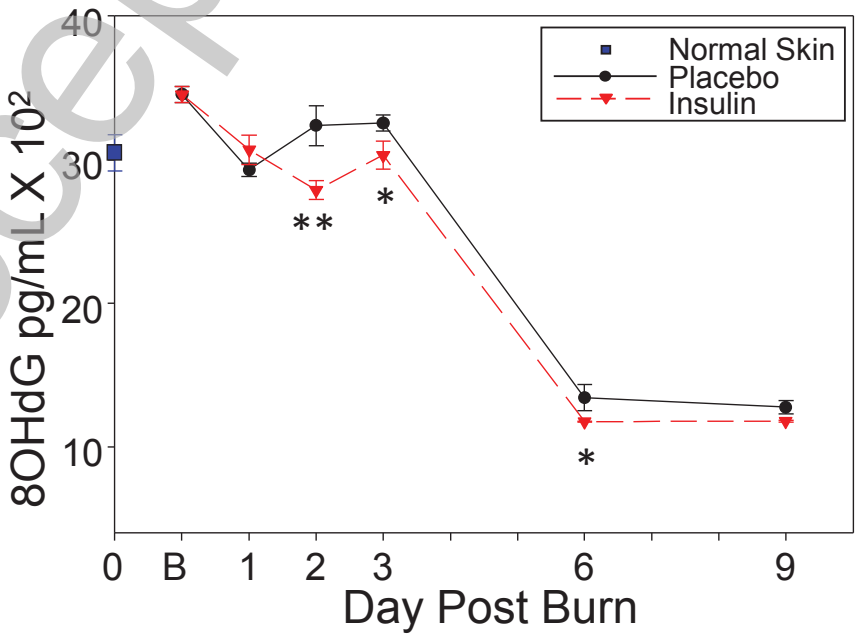

Figure 8 